Document downloaded from:

http://hdl.handle.net/10251/105309

This paper must be cited as:

Martinez Franco, R.; Paris, C.; Martínez-Triguero, J.; Moliner Marin, M.; Corma Canós, A. (2017). Direct synthesis of the aluminosilicate form of the small pore CDO zeolite with novel OSDAs and the expanded polymorphs. Microporous and Mesoporous Materials. 246:147157. doi:10.1016/j.micromeso.2017.03.014

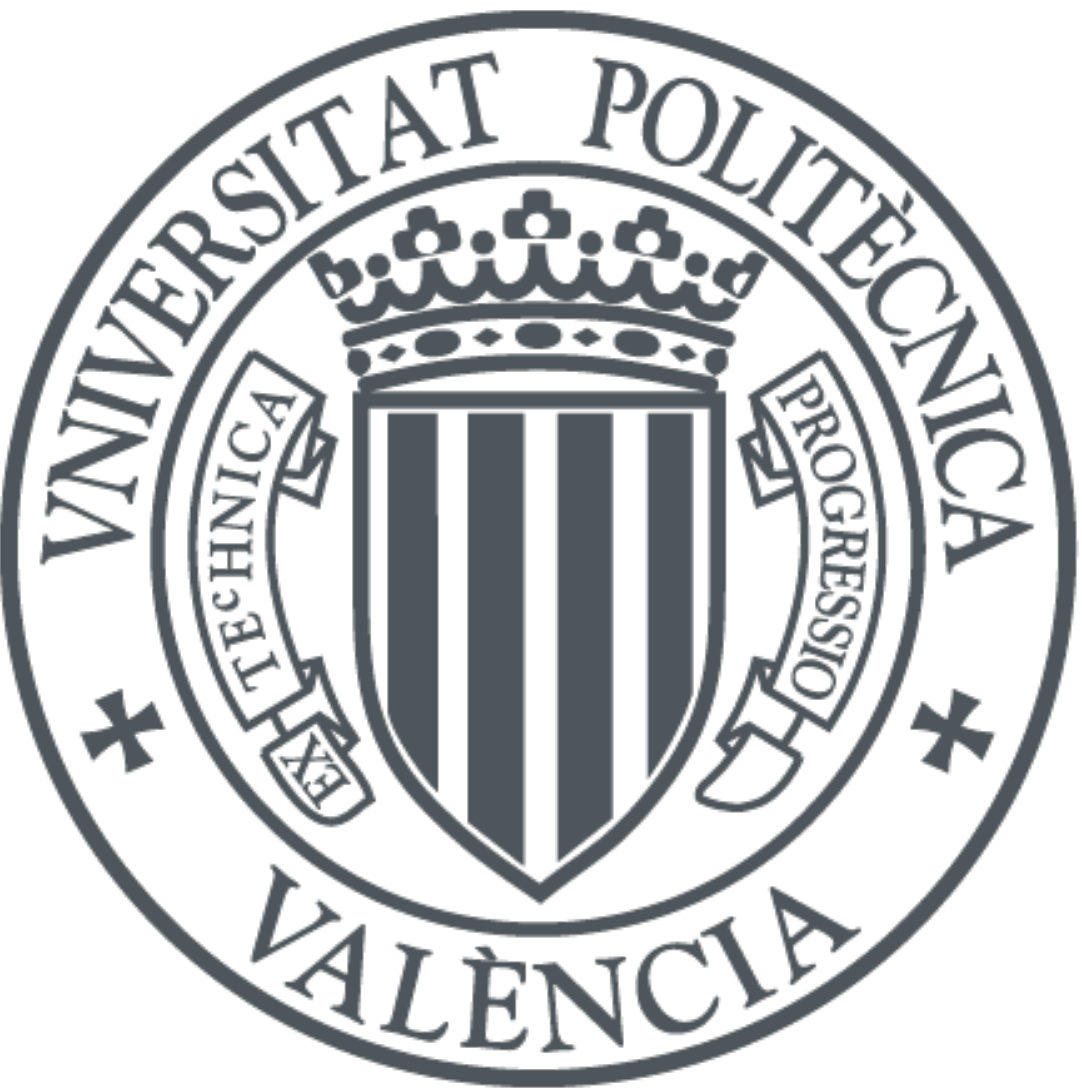

The final publication is available at

http://doi.org/10.1016/j.micromeso.2017.03.014

Copyright Elsevier

Additional Information 


\section{Direct synthesis of the aluminosilicate form of the small pore CDO zeolite with novel OSDAs and the expanded polymorphs}

Raquel Martínez-Franco, Cecilia Paris, Joaquin Martinez-Triguero, Manuel Moliner,* Avelino Corma*

Instituto de Tecnología Química, Universitat Politècnica de València-Consejo Superior de Investigaciones Científicas, Avenida de los Naranjos s/n, 46022 Valencia, España

KEYWORDS. Organic structure directing agents, small pore zeolite, interlayer expanded zeolite, methanol-to-olefins, selective catalytic reduction of NOx. 
ABSTRACT. A general procedure to synthesize the Al-containing layered CDO precursor (PreCDO) is presented, allowing its preparation under broad Si/Al molar ratios by using novel pyrrole-derived organic molecules as organic structure directing agents (OSDAs). The direct calcination of the PreCDO materials results in crystalline Al-containing small-pore CDO zeolites with controlled Al species in tetrahedral coordination. In contrast, mild acid treatments on the PreCDO materials allow achieving medium-pore interlayer expanded CDO zeolites (IEZ-CDO). These expanded zeolites show high crystallinity, high porosity and controlled Si/Al molar ratios. Finally, preliminary catalytic results indicate that the Al-containing CDO and IEZ-CDO samples show good activity and selectivity for the selective catalytic reduction (SCR) of NOx, and methanol-to-olefins (MTO) processes, respectively 


\section{1.- Introduction}

The design of new zeolite materials is usually undergone under hydrothermal synthesis conditions, starting from non-crystalline sources, and using organic molecules and hydroxyl or fluoride species as organic structure directing agents (OSDA) and mobilizing agents, respectively. ${ }^{1}$ Despite the important efforts to control the crystallization of zeolites with particular pore structures by direct synthesis, most of the zeolite structures are still being obtained following accumulated knowledge and trial and error methodologies. ${ }^{2}$

In the last years, new zeolite structures have been accomplished by structural conversion of layered zeolite precursors by topotactic dehydration-condensation of silanols. ${ }^{3}$ This methodology allows transforming lamellar zeolites containing silicate sheets into three-dimensional crystalline structures with specific pore architectures or chemical compositions by simple post-synthetic methods. ${ }^{3}$ Up to now, the following zeolite structures have been achieved from a layered precursor: AST, ${ }^{4} \mathrm{CAS},{ }^{5} \mathrm{CDO},{ }^{6}$ FER, ${ }^{7}$ MTF $,{ }^{8} \mathrm{MWW},{ }^{9} \mathrm{PCR},{ }^{10}, \mathrm{RRO},{ }^{11} \mathrm{RTH},{ }^{12} \mathrm{RWR},{ }^{13}$ or SOD. ${ }^{14}$

From all these structures, CDO-related materials have been extensively studied, because depending on the post-synthetic treatments, it is possible to design zeolitic structures with different pore topologies. The former lamellar-CDO precursor, named PLS-1, was described by Ikeda et al. in its pure silica form. ${ }^{6,15}$ This novel silicate lamellar material presents layers made of five-membered silicon rings, analogous to the layers of the PreFER material but with a different stacking order, ${ }^{7}$ containing the organic molecules within the interlayer region (see Figure 1A). Besides PLS-1, other CDO-related silicate layered materials have been reported in the literature, including, as-synthesized MCM$65,{ }^{16}$ as-synthesized MCM-47, ${ }^{17}$ or RUB-36. ${ }^{18}$

When the former layered silicate PLS-1 material was subjected to thermal treatments at temperatures above $400^{\circ} \mathrm{C}$, a new zeolitic structure, CDS-1 (CDO), was achieved by condensation of the pentasil layers. ${ }^{6}$ The crystalline structure of CDO is formed by the intersection of two straight small pore channels (8-rings) with pore openings of $3.1 \times 4.7$ $\AA$ and 2.5x4.2 $\AA .{ }^{6}$ Similar condensed small pore silicate CDO materials have been described in the literature by other groups, such as the calcined form of the MCM-65, ${ }^{16}$ the calcined form of the MCM-67 ${ }^{17}$ or RUB-37, ${ }^{18}$ after calcining their corresponding layered CDO precursors. 
Interestingly, different post-synthetic methods have been recently described to favor the expansion of the pore openings of the as-prepared lamellar precursors, such as using different pillaring molecules (dimethyldiethoxysilane or dichlorodimethylsilane) ${ }^{19}$ or self-pillaring by silicon migration during thermal acid treatments. ${ }^{15}$ These postsynthesis methods have allowed the synthesis of the interlayer-extended silicate form of the CDO, named as COE-4 ${ }^{20}$ or APZ-3, ${ }^{15}$ which presents two-dimensional 10-ring pores by the insertion of the $\mathrm{SiO}_{2}(-\mathrm{OH})_{2}$ linker between the pentasil layers (see Figure 1).

The introduction of aluminum species in tetrahedral coordination within the framework of the CDO-related structures would permit evaluating their potential use in catalysis. It is worth noting that different small pore (i.e. SSZ-13) ${ }^{21}$ and medium-pore aluminosilicates (i.e. MFI, MWW or FER), ${ }^{22}$ are being commercialized for several industrial processes, and thus, the synthesis of new small or medium pore zeolites presenting controlled Brönsted acidity is of great interest. However, as far as we know, the synthesis of the Al-containing small pore CDO material has not been accomplished, and only few reports can be found in the literature attempting the design of the pillared medium-pore CDO-related structure containing Brönsted acidity. ${ }^{23}$ In these cases, very low $\mathrm{Al}$ content has been introduced within the pillared CDO structure, both by direct synthesis (Al-COE-4, Si/Al ratio 100) ${ }^{23 a}$ and post-synthetic treatments (Al-PLS-1, $\mathrm{Si} / \mathrm{Al}$ ratio $>80),{ }^{23 \mathrm{~b}}$ thus presenting limited Brönsted acidity.

Herein, we describe a general and efficient procedure to achieve the synthesis of the aluminum-containing layered CDO precursor (PreCDO) under very broad Si/Al molar ratios (from 15 to 100), using novel pyrrole-derived organic molecules as OSDAs (see Figure 2). By direct calcination of these layered CDO precursors, well-crystalline aluminum-containing small-pore CDO materials with the entire aluminum atoms in tetrahedral coordination are achieved. It is worth noting that this is the first report describing the aluminum insertion within the small pore CDO zeolite. On the other hand, the synthesis of the pillared medium-pore Al-containing CDO materials has been achieved by subjecting the as-prepared layered PreCDO materials to mild acid treatments, followed by a calcination treatment. The resultant interlayer expanded CDO zeolites (IEZ-CDO) show high crystallinity, and controlled Si/Al molar ratios. The physico-chemical properties of the different materials have been characterized by several techniques, including Powder X-Ray Diffraction (PXRD), chemical analysis, $\mathrm{N}_{2}$ and Ar adsorption, Scanning Electron Microscopy (SEM), or solid-state nuclear 
magnetic resonance (NMR), among others. Preliminary catalytic results reveal that the Al-containing CDO and IEZ-CDO materials show good activity and selectivity for the selective catalytic reduction (SCR) of NOx, and methanol-to-olefins (MTO) processes, respectively.

\section{2.- Experimental Section}

\section{1.- OSDA syntheses}

General: unless otherwise stated, commercial reagents were used without further purification. (S)-(-)-1-Methyl-2-pyrrolidine methanol, iodomethane, iodoethane, chloroform, ethyl acetate and 2-propanol were purchased from Sigma-Aldrich.

The structure directing agents used in this work were synthesized as follow:

Synthesis of (S)-2-(hydroxymethyl)-1,1-dimethylpyrrolidin-1-ium hydroxide(OSDA1).

In a two-neck round flask equipped with a glass condenser, (S)-(-)-1-Methyl-2pyrrolidine methanol (12g, 0.104 moles) was dissolved in $300 \mathrm{ml}$ of chloroform. Iodomethane (29.6 g, 0.208 moles) was added dropwise, under constant and vigorous stirring. The solution was allowed to react one hour at $25^{\circ} \mathrm{C}$ and then at $40^{\circ} \mathrm{C}$ overnight. When the reaction was finished, a pale yellow oil was observed at the bottom of the flask. After evaporation of solvent and recrystallization with a ethyl acetate/2-propanol solution (70/30, \%V/V), (S)-2-(hydroxymethyl)-1,1-dimethylpyrrolidin-1-ium iodide was obtained as pale white crystals with $87.4 \%$ yield. The hydroxide form of the OSDA1 was prepared from batch ion-exchange using Amberlite IRN-78 resin (Supelco).

Synthesis of (2S)-1-ethyl-2-(hydroxymethyl)-1-methylpyrrolidin-1-ium hydroxide (OSDA2).

In a two-neck round flask equipped with a glass condenser, (S)-(-)-1-Methyl-2pyrrolidine methanol (12g, 0.104 moles) was dissolved in $350 \mathrm{ml}$ of chloroform. Iodoethane (32.5, 0.208 moles) was added dropwise, under constant and vigorous stirring. The mixture was left to react one hour at $25^{\circ} \mathrm{C}$ and then $24 \mathrm{~h}$ at $45^{\circ} \mathrm{C}$. Finally, once the crude reached room temperature, a second portion of iodoethane (8.13g, 0.052 moles) was added and then was left for another $24 \mathrm{~h}$. After this time, a pale yellow oil was formed. After evaporation of solvent, recrystallization of product as a mixture of diastereomers was achieved using an ethyl acetate/2-propanol solution (70/30, \%V/V). 
1-ethyl-2-(hydroxymethyl)-1-methylpyrrolidin-1-ium iodide was obtained as pale white crystals with $88.2 \%$ yield. The hydroxide form of the OSDA2 was prepared from batch ion-exchange using Amberlite IRN-78 resin (Supelco).

\section{2.- Zeolite syntheses}

In a typical synthesis, aluminum hydroxide $\left[\mathrm{Al}(\mathrm{OH})_{3}\right.$, Sigma-Aldrich] was dissolved in an aqueous solution of the OSDA in its hydroxide form. Colloidal silica (Ludox AS-40, Aldrich) was then added, and the mixture maintained under stirring for 20 minutes. Finally, a 10\%wt solution of $\mathrm{NH}_{4} \mathrm{~F}$ (Sigma-Aldrich) was added, and the resultant mixture gel was allowed to reach the desired silica to water ratio by evaporation under stirring. The final gel compositions were:

$\mathrm{SiO}_{2}: 0.005-0.033 \mathrm{Al}_{2} \mathrm{O}_{3}: 0.4 \mathrm{OSDA}(\mathrm{OH}): 0.4 \mathrm{NH}_{4} \mathrm{~F}: 3-15 \mathrm{H}_{2} \mathrm{O}$

where OSDA can be one of the molecules described above (see Figure 2).

Finally, the gels were transferred to Teflon lined stainless autoclaves and heated at $150^{\circ} \mathrm{C}$ for 10 days. The solids were recovered by filtration, extensively washed with distilled water, and dried at $90^{\circ} \mathrm{C}$ overnight.

For the direct synthesis of the Cu-containing CDO material, the required amount of the Cu-TEPA complex, which was prepared by mixing a $20 \%$ wt of an aqueous solution of copper (II) sulfate (98\%wt, Alfa) with tetraethylenepentamine (TEPA, 99\%wt, Aldrich), was added to the previously described synthesis gel. The final gel compositions were:

$\mathrm{SiO}_{2}: 0.033 \mathrm{Al}_{2} \mathrm{O}_{3}: 0.1 \mathrm{Cu}-\mathrm{TEPA}: 0.4 \mathrm{OSDA} 1(\mathrm{OH}): 0.4 \mathrm{NH}_{4} \mathrm{~F}: 3 \mathrm{H}_{2} \mathrm{O}$

where OSDA1 is the organic molecule shown in Figure 2.

The gel was transferred to Teflon lined stainless autoclaves and heated at $150^{\circ} \mathrm{C}$ for 10 days. The solids were recovered by filtration, extensively washed with distilled water, and dried at $90^{\circ} \mathrm{C}$ overnight. Finally, the Cu-containing CDO material is obtained by calcination in air at $550^{\circ} \mathrm{C}$.

\section{3.- Post-synthesis treatments}

The direct calcination of the layered PreCDO samples in air at $550^{\circ} \mathrm{C}$ for 4 hours results in the condensation of these lamellar precursor into small pore zeolites presenting the CDO structure. 
In contrast, the lamellar CDO precursors, PreCDO, can be transformed into the interlayer expanded CDO zeolites, IEZ-CDO, through an acid treatment followed by calcination. For this purpose, one gram of the PreCDO precursors was first mixed with $25 \mathrm{ml}$ of a 0.1 or $0.3 \mathrm{M}$ solution of hydrochloric acid. The mixture was placed in a Teflon-lined autoclave and heated while thumbing at $150^{\circ} \mathrm{C}$ or $175^{\circ} \mathrm{C}$ for 24 hours. The products were recovered by filtration, washed extensively with water and dried at $100^{\circ} \mathrm{C}$ overnight. The final solids were then calcined at $550^{\circ} \mathrm{C}$ for 4 hours in air.

\section{3.- Characterization}

Powder X-ray diffraction (PXRD) measurements were performed with a multisample Philips X'Pert diffractometer equipped with a graphite monochromator, operating at 45 $\mathrm{kV}$ and $40 \mathrm{~mA}$, and using $\mathrm{Cu} \mathrm{K} \alpha$ radiation $(\lambda=0,1542 \mathrm{~nm})$.

The chemical analyses were carried out in a Varian 715-ES ICP-Optical Emission spectrometer, after solid dissolution in $\mathrm{HNO} / \mathrm{HCl} / \mathrm{HF}$ aqueous solution. The organic content of the as-made materials was determined by elemental analysis performed on a SCHN FISONS elemental analyzer.

The morphology of the samples was studied by scanning electron microscopy (SEM) using a JEOL JSM-6300 microscope.

Textural properties were obtained from the $\mathrm{N}_{2}$ and Ar adsorption isotherms measured at 77 and 87 K, respectively, with a Micromeritics ASAP 2020 apparatus.

The solid-state NMR spectra were recorded at room temperature with a Bruker AV 400 MAS spectrometer. ${ }^{27} \mathrm{Al}$ MAS NMR spectra were recorded at $104.2 \mathrm{MHz}$ with a spinning rate of $10 \mathrm{kHz}$ and $9^{\circ}$ pulse length of $0.5 \mu$ s with a $1 \mathrm{~s}$ repetition time. ${ }^{13} \mathrm{C}$ MAS NMR cross-polarization (CP) spectrum was recorded at a sample spinning rate of $5 \mathrm{kHz} .{ }^{27} \mathrm{Al}$, and ${ }^{13} \mathrm{C}$ chemical shifts were referenced to $\mathrm{Al}^{3+}\left(\mathrm{H}_{2} \mathrm{O}\right)_{6}$, and adamantane, respectively.

\section{4.- Catalytic tests}

- Selective catalytic reduction (SCR) of NOx

The activity of the samples for the selective catalytic reduction (SCR) of NOx using $\mathrm{NH}_{3}$ as reductor was tested in a fixed bed, quartz tubular reactor of $1.2 \mathrm{~cm}$ of diameter and $20 \mathrm{~cm}$ length. The total gas flow was fixed at $300 \mathrm{ml} / \mathrm{min}$, containing $500 \mathrm{ppm}$ of 
NO, 530 ppm of $\mathrm{NH}_{3}, 7 \%$ of $\mathrm{O}_{2}$, and $5 \%$ of $\mathrm{H}_{2} \mathrm{O}$. The catalyst (100 mg) was introduced in the reactor, heated up to $450{ }^{\circ} \mathrm{C}$ and maintained at this temperature for one hour under nitrogen flow. Then, the desired reaction temperature was set $\left(250-450^{\circ} \mathrm{C}\right)$ and the reaction feed admitted. The NOx present in the outlet gases from the reactor were analyzed continuously by means of a chemiluminiscence detector (Thermo 62C).

- Methanol to olefins (MTO)

The catalyst was pelletized, crushed and sieved into 0.2-0.4 mm particle size. $50 \mathrm{mg}$ of sample was mixed with $2 \mathrm{~g}$ quartz (Fluka) before being introduced into the fixed-bed reactor $\left(7 \mathrm{~mm}\right.$ diameter). $\mathrm{N}_{2}(30 \mathrm{~mL} / \mathrm{min})$ was bubbled in methanol hold at $-17^{\circ} \mathrm{C}$, giving a WHSV $=0.8 \mathrm{~h}^{-1}$. The catalyst was first activated with a nitrogen flow of $80 \mathrm{ml} / \mathrm{min}$ for $1 \mathrm{~h}$ at $540^{\circ} \mathrm{C}$, and then the temperature was decreased to reaction conditions $\left(350^{\circ} \mathrm{C}\right)$. Each experiment was analyzed every 5 minutes with an online gas chromatograph (Bruker 450GC, with PONA and $\mathrm{Al}_{2} \mathrm{O}_{3}$-Plot capillary columns, and two FID detectors). After reaction, the catalyst was regenerated at $540^{\circ} \mathrm{C}$ in $80 \mathrm{ml}$ of air for $3 \mathrm{~h}$ and the reaction was repeated again. Preliminary experiments were carried out at constant WHSV, different amount of catalyst and increasing flow rates, and later with catalyst with in different particle sizes, to check that, at the selected reaction conditions the process is not controlled by either external or intraparticle diffusion. Conversion and selectivities were considered in carbon basis and methanol and dimethylether were lumped together for calculation of conversion.

\section{3.- Results}

\section{1.- Synthesis of the Al-containing small pore CDO zeolites}

Different synthesis variables, including the $\mathrm{Si} / \mathrm{Al}$ and $\mathrm{H}_{2} \mathrm{O} / \mathrm{Si}$ molar ratios, have been studied using the two organic molecules shown in Figure 2 as organic structure directing agents (OSDAs). As starting conditions, the $\mathrm{Si} / \mathrm{Al}$ and $\mathrm{H}_{2} \mathrm{O} / \mathrm{Si}$ molar ratios selected were $[15,30]$ and $[3,15]$, respectively, while maintaining the OSDA/Si and F/Si molar ratios both fixed at 0.4 , and the hydrothermal crystallizations at $150^{\circ} \mathrm{C}$ for 10 days under static conditions.

The materials achieved are summarized in Figure 3. It can be seen there the exclusive formation of amorphous phases when the synthesis gels were highly diluted (see $\mathrm{H}_{2} \mathrm{O} / \mathrm{Si}$ = 15), and the preferential crystallization of the lamellar precursor of CDO, PreCDO, 
with both OSDA molecules when the synthesis gels were concentrated (see $\mathrm{H}_{2} \mathrm{O} / \mathrm{Si}=$ 3). Up to now, and as far as we know, only one description can be found in the literature for the synthesis of the lamellar-CDO precursor in its silicoaluminate form, and in that case, a very limited and very high $\mathrm{Si} / \mathrm{Al}$ ratio was achieved $(\mathrm{Si} / \mathrm{Al} \sim 100) .{ }^{23 a}$ Thus, the novel pyrrole-derived organic molecules proposed in Figure 2 allow achieving the lamellar CDO precursor under remarkably lower Si/Al molar ratios than those described previously in the literature. In order to study if these organic molecules also allow synthesizing the PreCDO material under higher $\mathrm{Si} / \mathrm{Al}$ ratios, the preparation of this layered material with $\mathrm{Si} / \mathrm{Al}$ ratios of 50 and 80 has been attempted using the OSDA1 molecule as template. As seen in Figure 3, the layered PreCDO can also be obtained with high $\mathrm{Si} / \mathrm{Al}$ ratios when the synthesis gels have been prepared under concentrated conditions (see $\mathrm{H}_{2} \mathrm{O} / \mathrm{Si}=3$ ).

The PXRD patterns of selected as-prepared PreCDO zeolites show the crystallization of this layered material as pure crystalline phase (see PXRD patterns of PreCDO_1, PreCDO_2 and PreCDO_3 in Figure 4A). The study of these PreCDO materials by scanning electron microscopy (SEM) reveals the formation in all cases of very small crystals $(\sim 0.1-0.2 \mu \mathrm{m}$, see Figures 5A-C).

The stability of the organic molecules after the hydrothermal crystallizations has been evaluated by elemental analyses and solid-state ${ }^{13} \mathrm{C}$ MAS NMR spectroscopy. The elemental analyses of the PreCDO_1 and PreCDO_2 samples give similar carbon and nitrogen content in both as-prepared solids ( 2.1-2.2\%wt and $\sim 14-15 \%$ wt, respectively, see Table 1). Interestingly, their measured $\mathrm{C} / \mathrm{N}$ molar ratio is 7.7 (see Table 1), which is very similar to the expected theoretical $\mathrm{C} / \mathrm{N}$ molar ratio for the OSDA2 molecule $(\mathrm{C} / \mathrm{N}=8)$. In contrast, the as-prepared PreCDO_3 sample shows slightly higher of carbon and nitrogen contents ( 2.7\%wt and $\sim 16 \%$ wt, respectively, see Table 1$)$. The relative lower size of the OSDA1 compared to the OSDA2, could explain the larger organic content within the interlayer region of the PreCDO_3 sample. The measured C/N molar ratio for the as-prepared PreCDO_3 material is 6.9 (see Table 1), which is analogous to the expected theoretical $\mathrm{C} / \mathrm{N}$ molar ratio for the OSDA1 molecule $(\mathrm{C} / \mathrm{N}=7)$. On the other hand, the solid-state ${ }^{13} \mathrm{C}$ MAS NMR spectrum of the as-prepared PreCDO_3 solid shows the same signals than those observed by liquid ${ }^{13} \mathrm{C}$ NMR spectroscopy for the 
aqueous solution of the OSDA1 molecule (see Figure 6). These results confirm that the pyrrole-derived molecules remain intact and undamaged within the final solids.

Since the three selected PreCDO materials have been prepared under different $\mathrm{Si} / \mathrm{Al}$ molar ratios (see Figure 3), the samples have been characterized by ICP to evaluate their final chemical composition. As seen in Table 2, the measured Si/Al molar ratios are 14.2, 32.1 and 47.3 for the PreCDO_1, PreCDO_2 and PreCDO_3, respectively, which are comparable to the theoretical $\mathrm{Si} / \mathrm{Al}$ values introduced in the initial synthesis gels (see Figure 3). Moreover, the solid-state ${ }^{27} \mathrm{Al}$ MAS NMR spectra of these layered precursors reveal the exclusive presence of tetrahedrally-coordinated aluminum atoms in framework positions (see the signals centered at 47 ppm for PreCDO_1, and PreCDO_2 in Figure 7).

The direct calcination in air at $550^{\circ} \mathrm{C}$ for 4 hours of the three lamellar PreCDO materials results in their interlayer condensation, which induces the formation of the 3dimensional crystalline structure of CDO by topotactic transformation (see Figure 1B). The PXRD patterns of these calcined materials confirm the presence of the CDO phase as pure crystalline phase in all cases (see Figure 4b). The CDO framework is formed by two straight small channels of 8-ring openings along the [010] and [001] directions.

To evaluate the textural properties of these CDO materials, the calcined CDO_1 and CDO_2 samples have been analyzed by $\mathrm{N}_{2}$ adsorption. The measured BET and micropore areas for the CDO materials are ranged between 260-290 and 190-215 m²/g, respectively, whereas the micropore volumes are between $0.09-0.11 \mathrm{~cm}^{3} / \mathrm{g}$ (see CDO_1, and CDO_2 in Table 3). Similar values have been described previously in the literature for the pure silica form of CDO. ${ }^{[24]}$

It is worth noting that these CDO materials are the first examples describing the introduction of aluminum atoms within the structure of this small-pore zeolite. The final $\mathrm{Si} / \mathrm{Al}$ molar ratios of the condensed materials are exactly the same than the Si/Al molar ratios of their corresponding previous layered precursors (see Table 2). Moreover, the characterization of the Al-containing small pore CDO samples by solid-state ${ }^{27} \mathrm{Al}$ MAS NMR spectroscopy reveals that, regardless the $\mathrm{Si} / \mathrm{Al}$ ratio, almost the entire $\mathrm{Al}$ species remain in tetrahedral coordination within the zeolitic CDO frameworks (see the main signal centered at -47 ppm for CDO_1, and CDO_2 in Figure 7). 
Therefore, the general synthesis procedure described here to achieve the Al-containing small pore CDO zeolite with controlled amounts of aluminum species in framework positions allows envisioning that this material could find interesting applications as catalyst, gas separator or ion-exchanger for industrially-relevant processes, as has recently been shown for other related small-pore zeolites. ${ }^{21}$

\section{2.- Synthesis of the Al-containing medium pore interlayer expanded-CDO (IEZ- CDO) zeolites}

Besides the small pore CDO zeolite, it has been reported in the literature that the lamellar precursor of CDO can also be transformed into a medium pore zeolite by an interlayer expansion of the initial silicate layers. ${ }^{15,19,20}$ Following these previous synthesis descriptions in the literature, a very small amount of aluminum can be introduced within the expanded CDO materials, presenting the final acid solids Si/Al molar ratios above $100,{ }^{23}$ and, therefore, limited acid properties.

As it has been shown above, using the pyrrole-derived organic molecules as OSDAs, we have been able to synthesize the layered precursors of $\mathrm{CDO}$ with controlled Si/Al ratios (from 15 to 80, see Figure 3). These Al-containing PreCDO materials could be taken as initial precursors to attempt the preparation of the Al-containing expanded CDO zeolites by following a post-synthetic interlayer expansion.

In the last years, different research groups have described the zeolitic interlayer expansion by assembling the diverse layered silicate precursors through acid treatments. ${ }^{15,19 b, d, 25}$ These acid treatments allow dissolving very small fragments of the initial silicate substrate, providing the required species to undergo the "self-pillaring” of the zeolitic layers. In this sense, two different silanol groups (Sil-OH) from adjacent layers are connected by one-atom pillar, forming the linkage [Sil-O-Si(OH)$\left.)_{2}-\mathrm{O}-\mathrm{Sil}\right]$, and then, resulting in an increase of the pore size compared to the condensed CDO materials achieved through direct calcination treatments.

The "self-pillaring" chemistry of the layered CDO precursors has been studied by treating hydrothermally these as-prepared precursors with solutions of $\mathrm{HCl}(0.1-0.3 \mathrm{M})$ at a given temperature $\left(150-175^{\circ} \mathrm{C}\right)$ for 24 hours. After performing the hydrothermal acid treatments, the samples were washed and filtered, and the resulting solids were characterized by PXRD. The PXRD patterns of the acid-treated PreCDO materials are similar to the PXRD patterns of the formed PreCDO precursors (see PreCDO_1_Ac, 
PreCDO_2_Ac and PreCDO_3_Ac in Figures 8, 9, and 10, respectively). If this acidtreated layered CDO precursors are then subjected to a calcination treatment in air at $550^{\circ} \mathrm{C}$ for 4 hours, it can be clearly seen that the calcined materials retain the first peak of their PXRD patterns at lower $2 \theta$ angles (see IEZ-CDO_1,_2 and _3 in Figures 8, 9, and 10, respectively), indicating that the contraction of the initial lamellar materials into condensed CDO structure is not occurring. Though the PXRD patterns of the three IEZCDO materials do not show the presence of the condensed CDO zeolite, the crystallinity observed for the IEZ-CDO_1 material (see PXRD pattern in Figure 8), is lower than the crystallinity observed for IEZ-CDO_2 and IEZ_CDO_3 (see PXRD patterns in Figure 9 and 10, respectively). This would indicate that the amount of aluminum species in framework positions of the CDO precursors may influence the “self-pillaring” process, resulting in less-ordered expanded IEZ-CDO samples when decreasing the $\mathrm{Si} / \mathrm{Al}$ ratio. Indeed, it is worth noting that the acid treatment on the PreCDO_1 sample should be performed at lower temperature $\left(150^{\circ} \mathrm{C}\right)$, because otherwise the formation of the condensed CDO zeolite was already observed.

The textural properties of the expanded IEZ-CDO materials have been measured by $\mathrm{N}_{2}$ and Ar adsorption to evaluate their pore accessibility. The IEZ-CDO_1 and _2 samples show very similar $\mathrm{N}_{2}$ adsorption isotherms, with comparable $\mathrm{N}_{2}$ absorption uptakes at low relative pressures (see Figure 11). The micropore area and micropore volume for the IEZ-CDO_2 material is slightly higher $\left(\sim 253 \mathrm{~m}^{2} / \mathrm{g}\right.$ and $\sim 0.12 \mathrm{~cm}^{3} / \mathrm{g}$, see Table 3) than those observed for the IEZ-CDO_1 sample $\left(\sim 220 \mathrm{~m}^{2} / \mathrm{g}\right.$ and $\sim 0.11 \mathrm{~cm}^{3} / \mathrm{g}$, see Table 3). This issue could be explained by the lower crystallinity achieved for the IEZ-CDO_1 sample after the "self-pillaring" process. On the other hand, the characterization of the IEZ-CDO_2 sample using Ar adsorption reveals a very narrow pore size distribution along this zeolitic material, with an average pore size of $5.4 \AA$ (see Figure 12). This experimentally measured pore size distribution by Ar adsorption, typically observed for medium-pore zeolites, undoubtedly proves the pore expansion achieved for the IEZCDO samples.

The Si/Al molar ratios of the expanded IEZ-CDO materials have been measured by ICP, resulting in 19.2, 38.2 and 47.3, for the IEZ-CDO_1,_2 and_3, respectively (see Table 2). These values are very similar to the initial $\mathrm{Si} / \mathrm{Al}$ ratios of the corresponding layered precursors (see Si/Al ratios of PreCDO_1,_2, and _3 in Table 2), indicating that the chemical composition of the zeolites is mostly preserved during the acid "self- 
pillaring” treatments. Furthermore, most of the aluminum species remain in framework positions after the hydrothermal acid treatments, as revealed by the solid state ${ }^{27} \mathrm{Al}$ MAS NMR spectra of the expanded IEZ-CDO materials (see main band at $\sim 50 \mathrm{ppm}$ for IEZ-CDO_1,_2 and_3 in Figure 7). The quantification of the signals observed in the ${ }^{27} \mathrm{Al}$ MAS NMR spectra indicates that the percentage of aluminum remaining in tetrahedral coordination is $~ 70 \%, ~ 85 \%$, and $~ 95 \%$, for the IEZ-CDO_1, IEZ-CDO_2 and IEZ-CDO_3 samples.

Thus, following a very simple post-synthetic acid treatment of the Al-containing layered precursors of CDO, it has been possible to obtain well-structured medium pore zeolites presenting two straight channels and controlled $\mathrm{Si} / \mathrm{Al}$ ratios.

\section{3.- Preliminary catalytic results of the Al-containing CDO and IEZ-CDO materials}

\subsection{1.- Selective catalytic reduction (SCR) of NOx}

In the last years, different copper-containing small pore zeolites presenting low $\mathrm{Si} / \mathrm{Al}$ molar ratios have been reported as very active and stable catalysts for the selective catalytic reduction (SCR) of NOx with ammonia. ${ }^{21,26}$ In this sense, the ability of preparing the small pore $\mathrm{CDO}$ zeolite with low $\mathrm{Si} / \mathrm{Al}$ ratios opens the possibility of introducing copper cations in extra-framework positions within the Al-CDO material for its use as catalyst for $\mathrm{NH}_{3}$-SCR. From the different methods to introduce the copper within the zeolitic structures, the one-pot synthesis methods using $\mathrm{Cu}$-complexes in the synthesis media have been shown as one of the most efficient methods, since the copper species can be better dispersed along the zeolitic crystals. ${ }^{27}$

Having that in mind, the direct synthesis of the Cu-containing CDO material has been attempted using the complex formed by copper and tetraethylenepentamine molecules (Cu-TEPA) under the following synthesis conditions: $\mathrm{SiO}_{2}: 0.033 \mathrm{Al}_{2} \mathrm{O}_{3}: 0.1 \mathrm{Cu}-$ TEPA : 0.4 OSDA1 $(\mathrm{OH}): 0.4 \mathrm{NH}_{4} \mathrm{~F}: 3 \mathrm{H}_{2} \mathrm{O}$, where the hydrothermal crystallization has been undergone at $150^{\circ} \mathrm{C}$ for 10 days. The PXRD pattern of the resultant solid shows the formation of the lamellar precursor of CDO (see Cu-PreCDO in Figure 13). Moreover, the diffuse-reflectance UV-Vis spectrum of the as-prepared Cu-PreCDO material indicates that the Cu-TEPA molecules remain intact within the lamellar precursor, as revealed by the presence of the band centered at $270 \mathrm{~nm}$, which is characteristic of the Cu-TEPA complex molecules (see Cu-TEPA and Cu-PreCDO in Figure 14). ${ }^{27}$ 
The Cu-containing lamellar precursor is condensed into a Cu-containing CDO material after being subjected to a calcination treatment in air at $550^{\circ} \mathrm{C}$ (see PXRD pattern of $\mathrm{Cu}-$ CDO in Figure 13). The chemical analysis of the small-pore $\mathrm{Cu}-\mathrm{CDO}$ zeolite gives a $\mathrm{Si} / \mathrm{Al}$ molar ratio and a copper content of 13.3 and 5.3\%wt, respectively (see Table 2). The catalytic activity of this Cu-CDO material has been tested for the SCR of NOx with ammonia, achieving NO conversion values close to $90 \%$ for intermediate reaction temperatures (350- $400^{\circ} \mathrm{C}$, see Figure 15$)$. These preliminary results reveal that the $\mathrm{Cu}-$ CDO shows good catalytic properties for the SCR of NOx. The improvement of the catalytic activity of the Cu-containing CDO material through optimizing the synthesis conditions of its one-pot preparation is currently being intensively studied within our group.

\subsection{2.- Methanol-to-olefins (MTO) reaction}

Since 8- and 10-ring zeolites (SAPO-34 and ZSM-5, respectively) are used as commercial catalysts for the methanol-to-olefins (MTO) reaction, CDO-derived zeolites have been studied for the conversion of methanol. The condensed small pore CDO_1 sample shows very low methanol conversion (22\%, see CDO in Table 4). Similar results have been previously observed for another high silica CDO catalyst, ${ }^{28}$ attributing the low catalytic activity to the lack of cavities in the crossing of the 8-ring structure, which hinders the formation of the required polymethylbenzenes intermediates. Other 8ring pore zeolites with small or no cavities, as MTF, also present very low initial methanol conversions. ${ }^{29}$ Interestingly, after expanding the CDO material to IEZ-CDO, the methanol conversion raises, achieving almost full methanol conversion for the IEZCDO sample with a Si/Al ratio of 30 (see IEZ-CDO_30 in Table 4). The IEZ-CDO_2 material shows a remarkably catalyst deactivation after TOS of 60 minutes.

The product yields achieved for the different CDO-related materials are shown in Table 4. The small pore CDO zeolite presents high selectivity to ethylene, whereas the IEZCDO materials show higher selectivity to propylene than ethylene, particularly for the IEZ-CDO with a $\mathrm{Si} / \mathrm{Al}$ ratio of 30 (see Table 4). It is important to note that, despite the expansion to the 10-ring bidimensional channel, there is no presence of aromatics in the products of both IEZ-CDO materials. It appears that the bidimensional 10-ring channels present tortuosity or the size of the rings is too small to favor its diffusion out of the crystallites. In the case of IEZ-CDO_1, the selectivity to ethylene is closer to that of propylene and there is an important contribution of methane and paraffins. On the 
contrary, the IEZ-CDO_2 catalyst shows a higher selectivity to propylene and the yield to C1+paraffins is lower (see Table 4). The differences in the selectivity of the expanded materials could be explained taking into account the different contribution of the olefin and the aromatic cycles of the hydrocarbon pool that lead the selectivity especially in 10-zeolites as for instance ZSM-5. At lower Si/Al ratios, that means higher acid density, the aromatic cycle of polymethylbenzenes dominates, with higher yields of ethylene, while at higher $\mathrm{Si} / \mathrm{Al}$ ratios ethylene decreases and propylene is the main product.

The hydrogen transfer ratios, expressed as ratios of paraffins to olefins in the C2, C3 and C4 fractions, are shown in Figure 16. The small pore CDO material shows lower hydrogen transfer ratios compared to the expanded materials due to the restricted space with no cavities, precluding the bimolecular reactions. After the expansion to IEZ-CDO, the hydrogen transfer strongly increases for both materials, but particularly for the IEZCDO_15 sample (see Figure 16). This fact would explain its faster catalyst deactivation, probably by its higher Brönsted acidity.

In summary, the CDO-related materials enhance their catalytic activity for the conversion of methanol to olefins when their pore sizes are expanded from 8- to 10-ring pores, as it is the case of the IEZ-CDO materials. However, at the moment, their performance is far from SSZ-13 and ZSM-5 in terms of lifetime and, therefore, in methanol conversion capacity. The optimization of the MTO performance of the new IEZ-CDO zeolite is now being studied, attempting to decrease the undesired hydrogen transfer reactions.

\section{4.- Conclusions}

The synthesis of the Al-containing layered CDO precursor (PreCDO) has been obtained in a broad range of $\mathrm{Si} / \mathrm{Al}$ molar ratios by using novel pyrrole-derived organic molecules as OSDAs. The direct calcination of the PreCDO results in the formation of Alcontaining small-pore CDO materials with the Al species in tetrahedral coordination. A post-synthetic mild acid treatment on the PreCDO materials allows achieving mediumpore interlayer expanded CDO zeolites (IEZ-CDO). These expanded materials show high crystallinity, excellent pore distribution and controlled Si/Al molar ratios. These Al-containing CDO and IEZ-CDO materials have been evaluated for the selective catalytic reduction (SCR) of NOx, and methanol-to-olefins (MTO) reactions. 
Preliminary catalytic results reveal that these Al-containing CDO-related materials are active and selective for these processes.

FIGURES.

Figure 1. Structures of the lamellar precursor of CDO (PreCDO, A), small-pore CDO zeolite (CDO, B) and interlayer expanded CDO zeolite (IEZ-CDO, C).

(A)

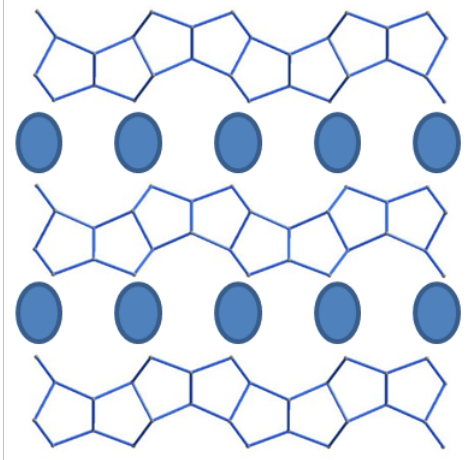

Pre-CDO
(B)

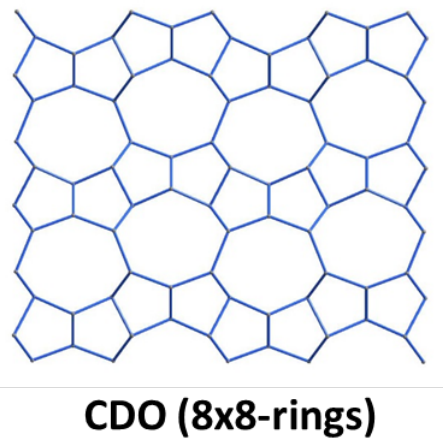

(C)

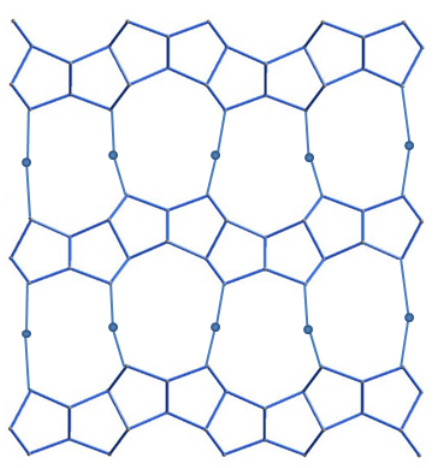

IEZ-CDO (10x10-rings) 
Figure 2. Organic structure directing agents used for the synthesis of CDO-type zeolite.

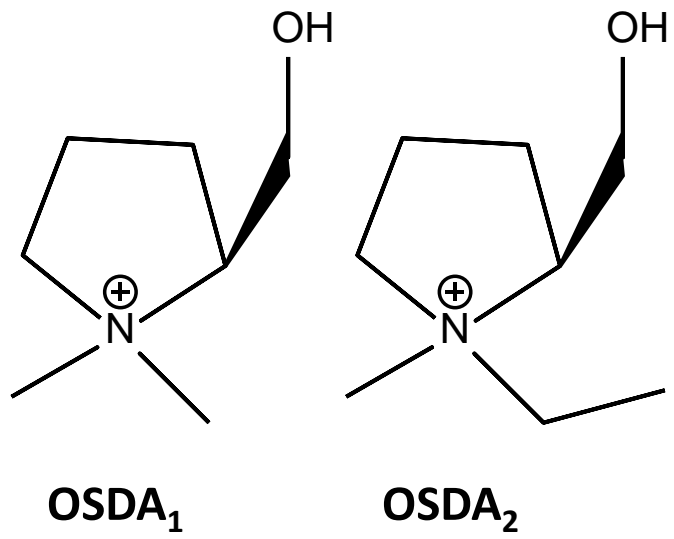


Figure 3. Phase diagrams obtained using OSDA1 (A) and OSDA2 (B) as organic structure directing agents.

(A)

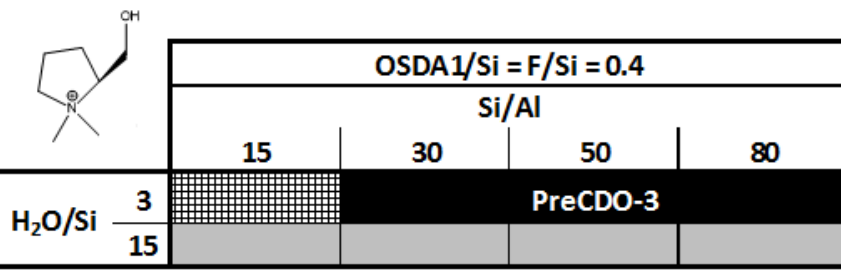

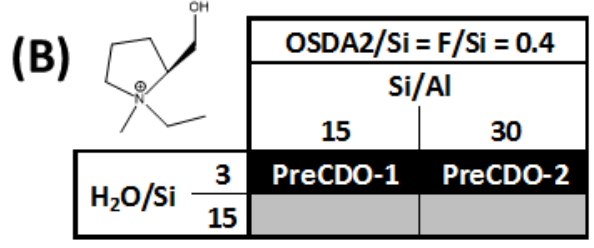

\begin{tabular}{|l} 
Amorphous \\
PreCDO+ Lamellar \\
PreCDO
\end{tabular}


Figure 4. PXRD patterns of the as-prepared (A) and calcined (B) CDO-type zeolite.
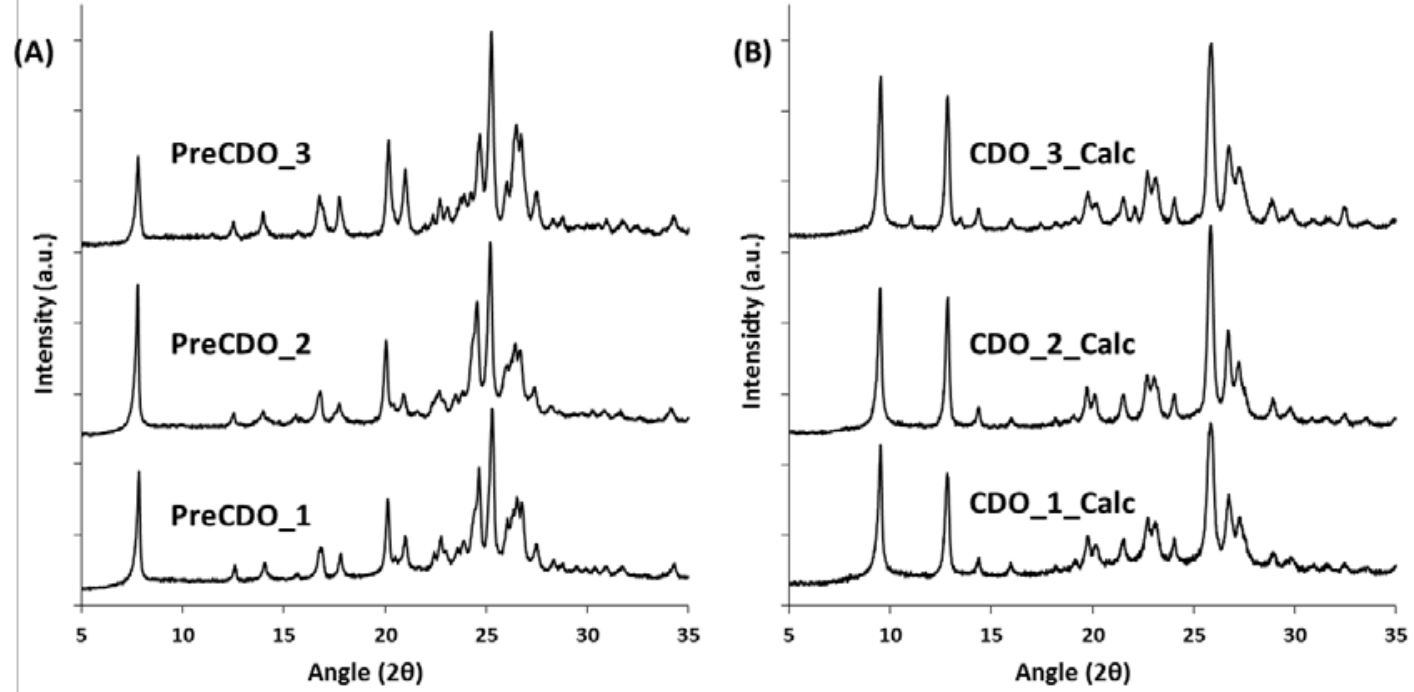
Figure 5. SEM images of the as-prepared PreCDO_1(A), PreCDO_2 (B), and PreCDO_3 (C).
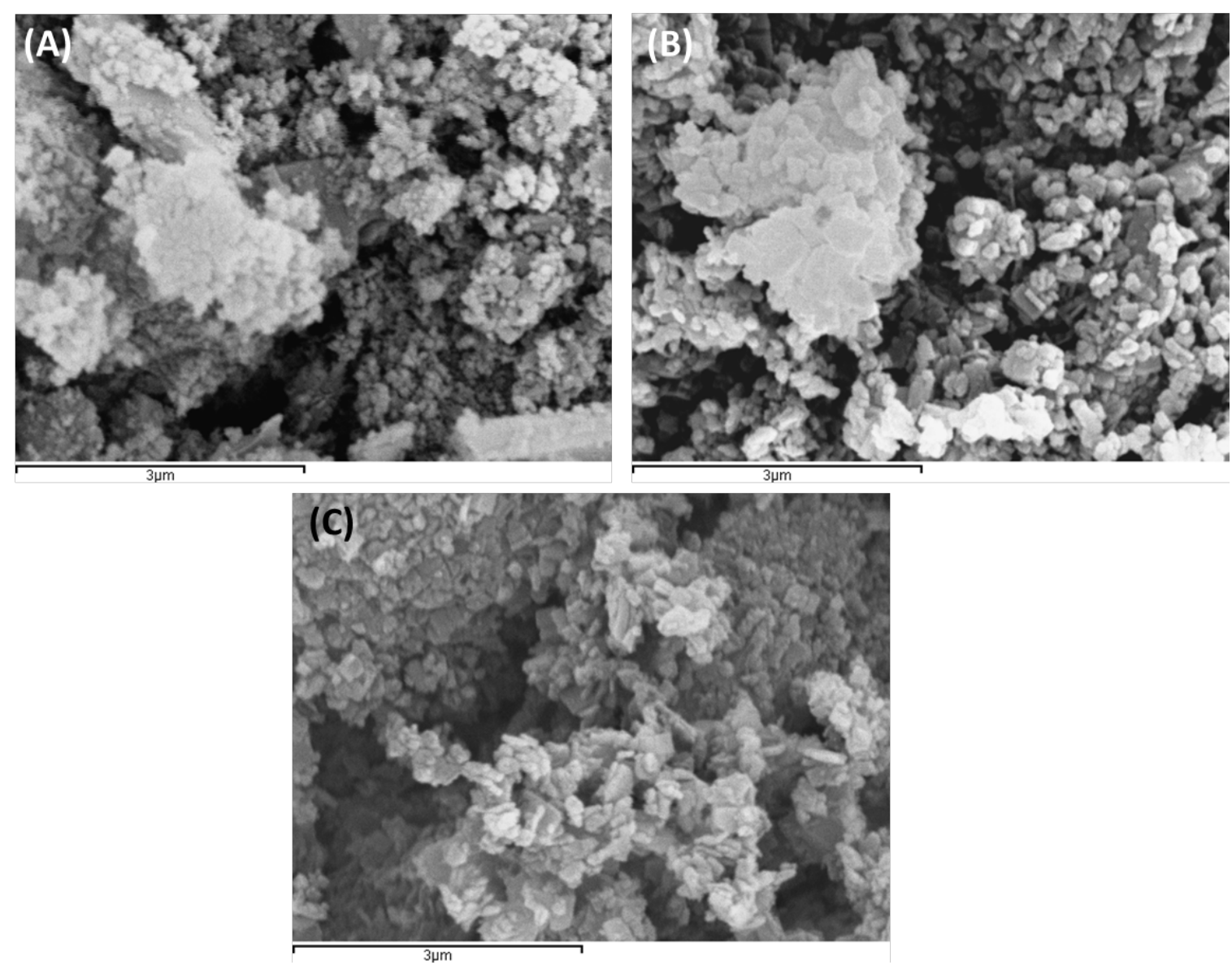
Figure 6. Liquid ${ }^{13} \mathrm{C}$ NMR of the aqueous solution of the OSDA1 and solid-stated ${ }^{13} \mathrm{C}$ MAS NMR spectra of the as-prepared PreCDO_3 material.

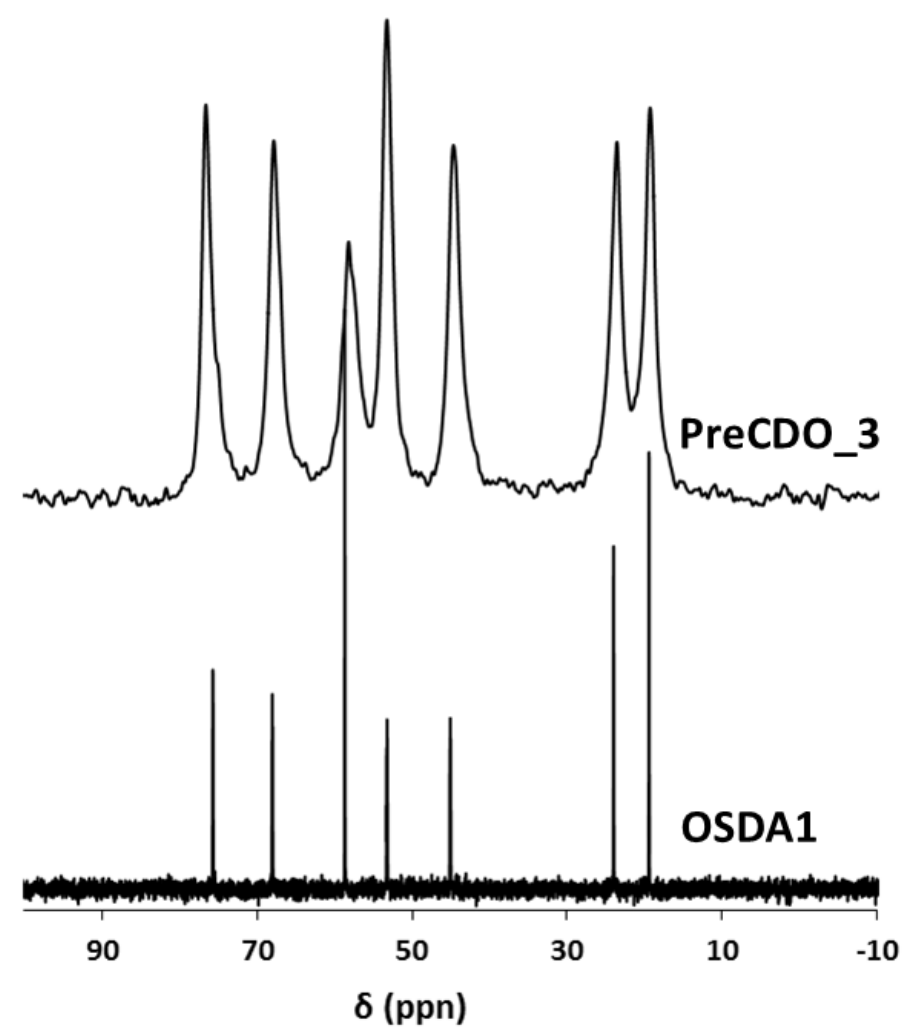


Figure 7. ${ }^{27} \mathrm{Al}$ MAS NMR spectra of the as-prepared and calcined CDO-type zeolite.

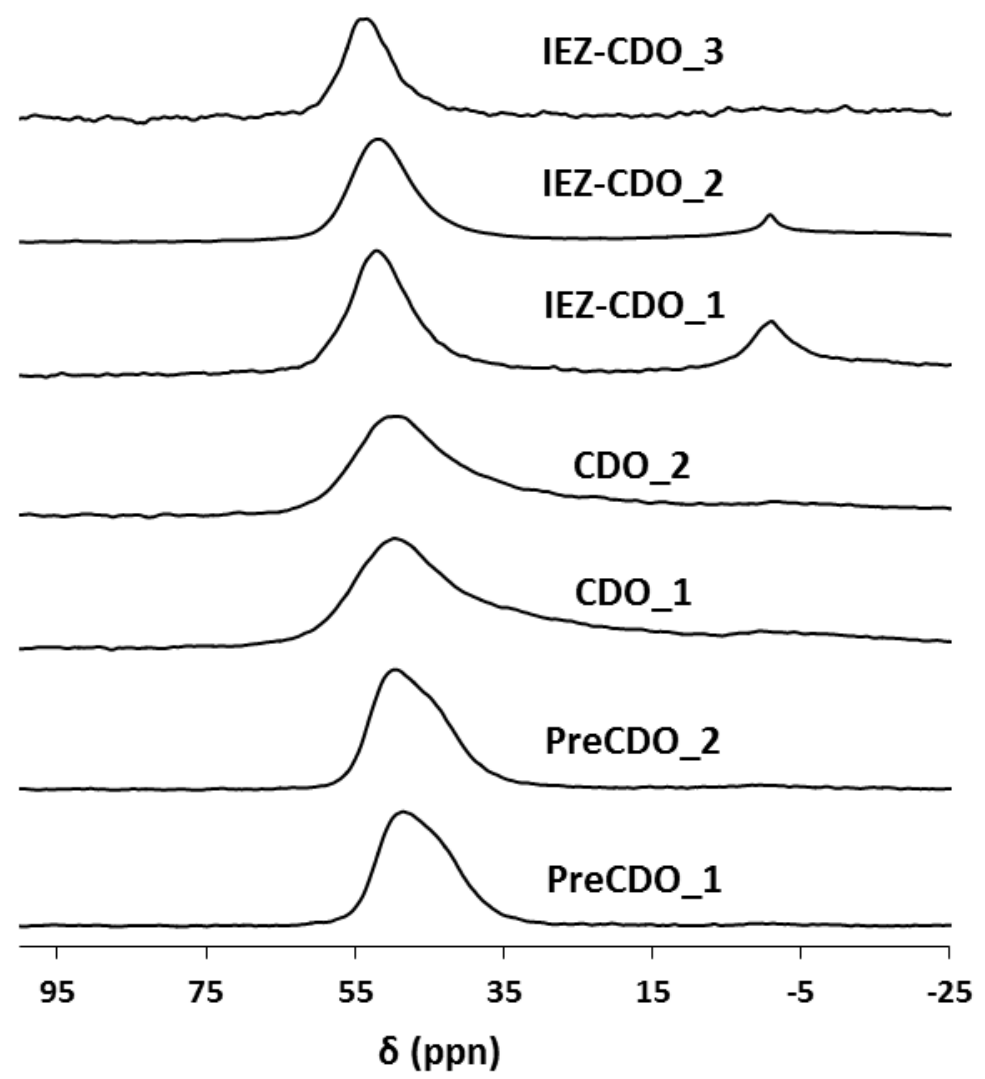


Figure 8. PXRD patterns of the PreCDO_1 material after different post-synthetic treatments.

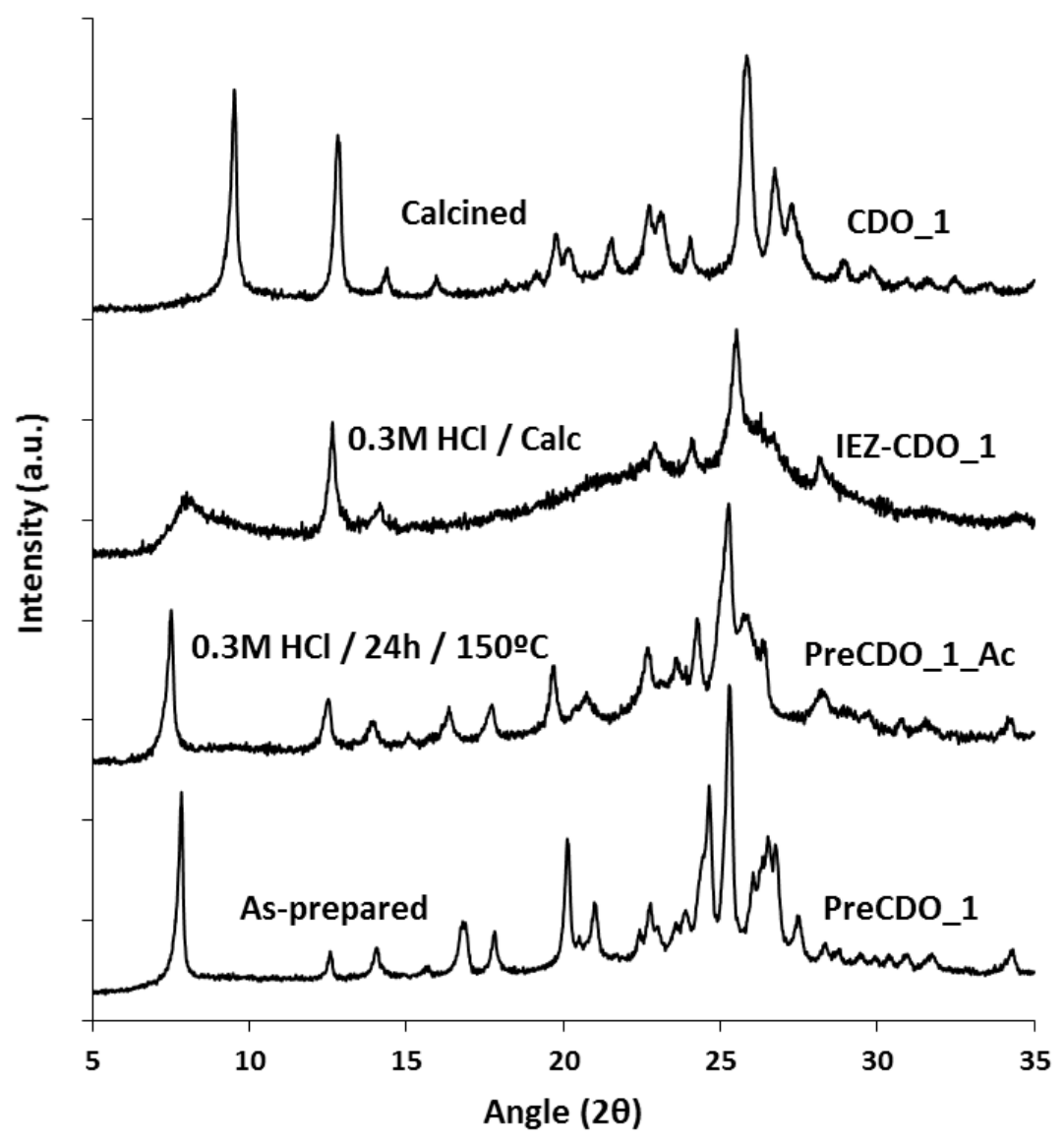


Figure 9. PXRD patterns of the PreCDO_2 material after different post-synthetic treatments.

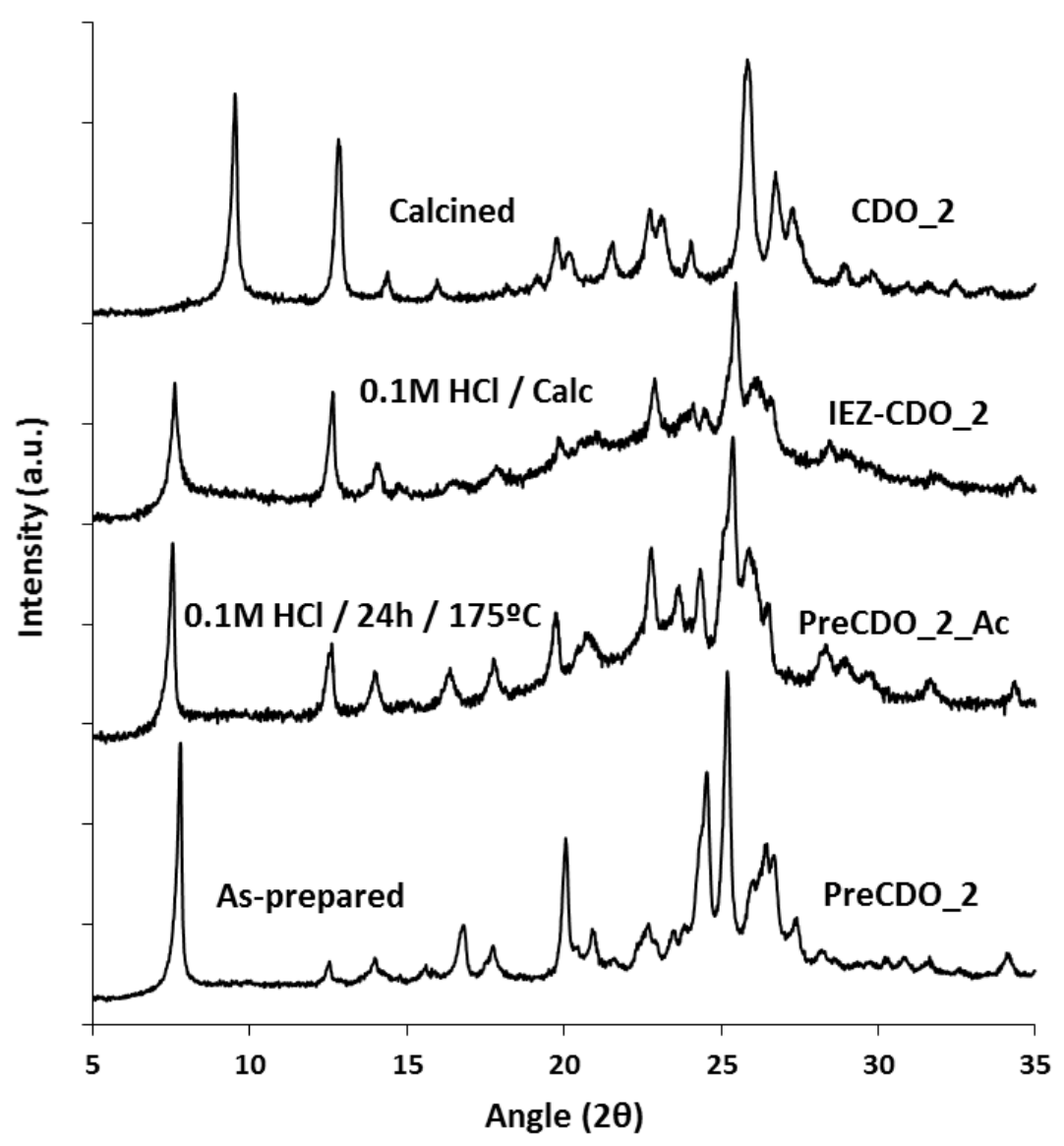


Figure 10. PXRD patterns of the PreCDO_3 material after different post-synthetic treatments.

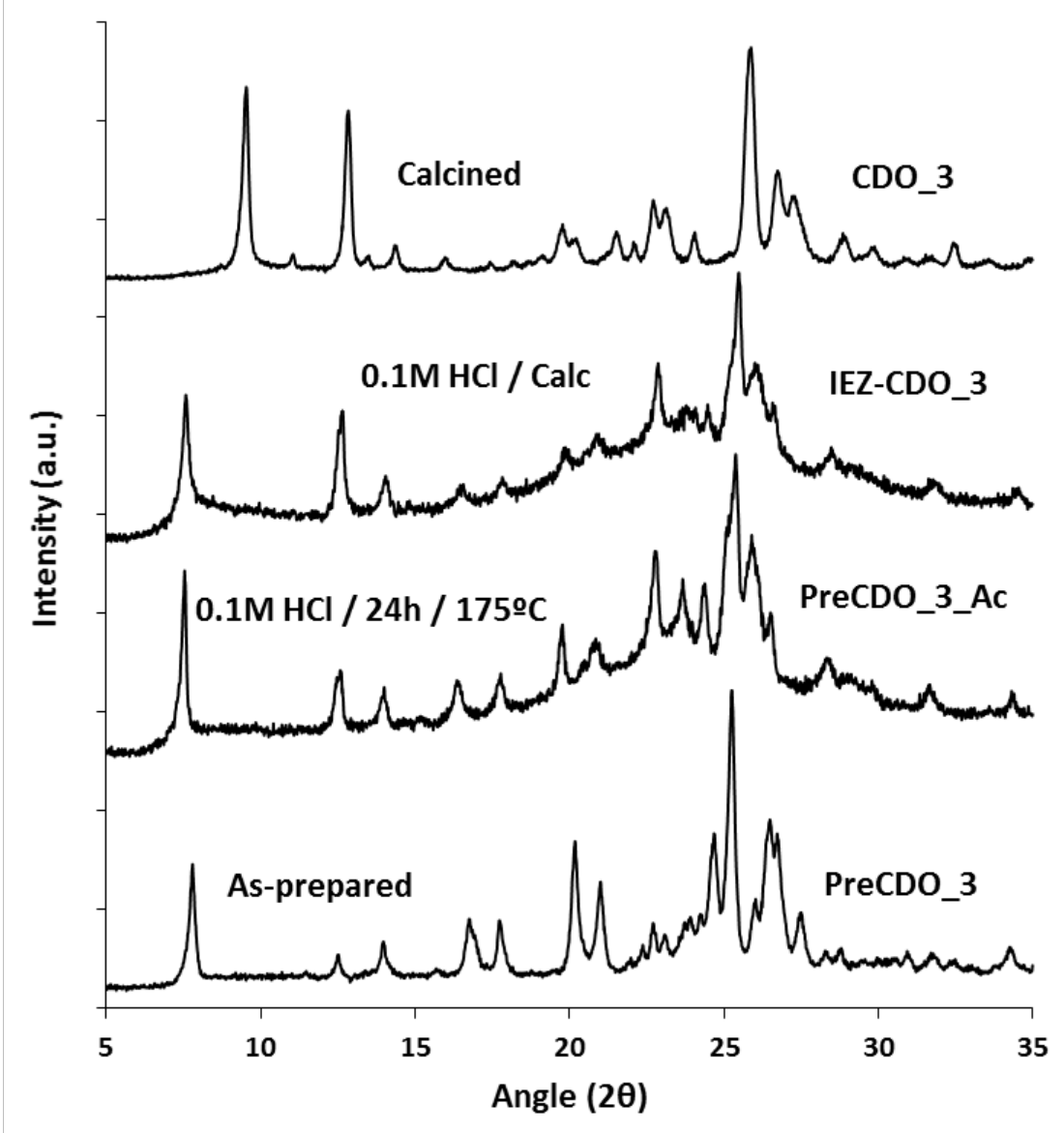


Figure 11. $\mathrm{N}_{2}$ adsorption isotherms of the expanded CDO-type zeolites.

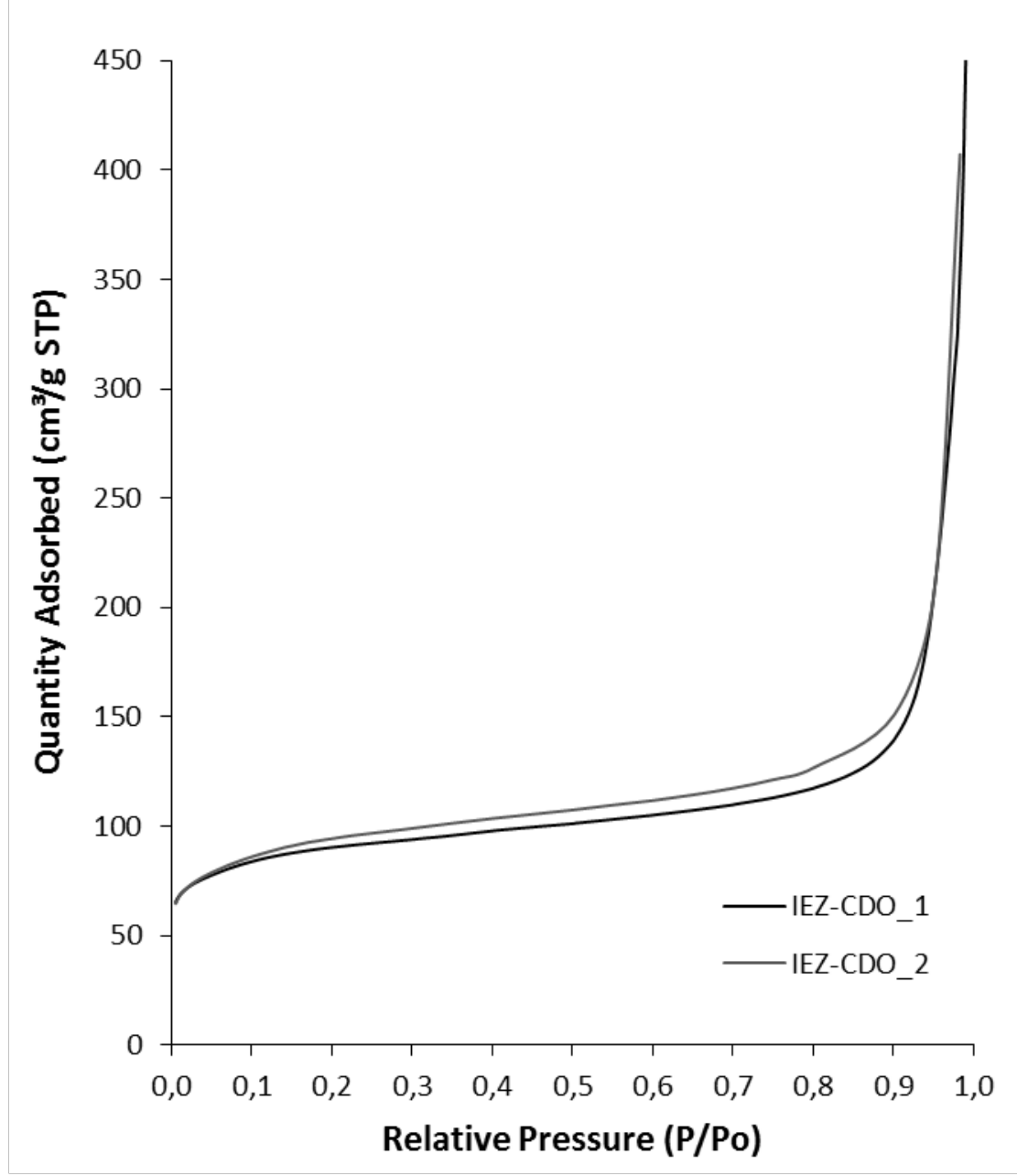


Figure 12. Pore size distribution of the IEZ-CDO_2 sample measured by Ar adsorption.

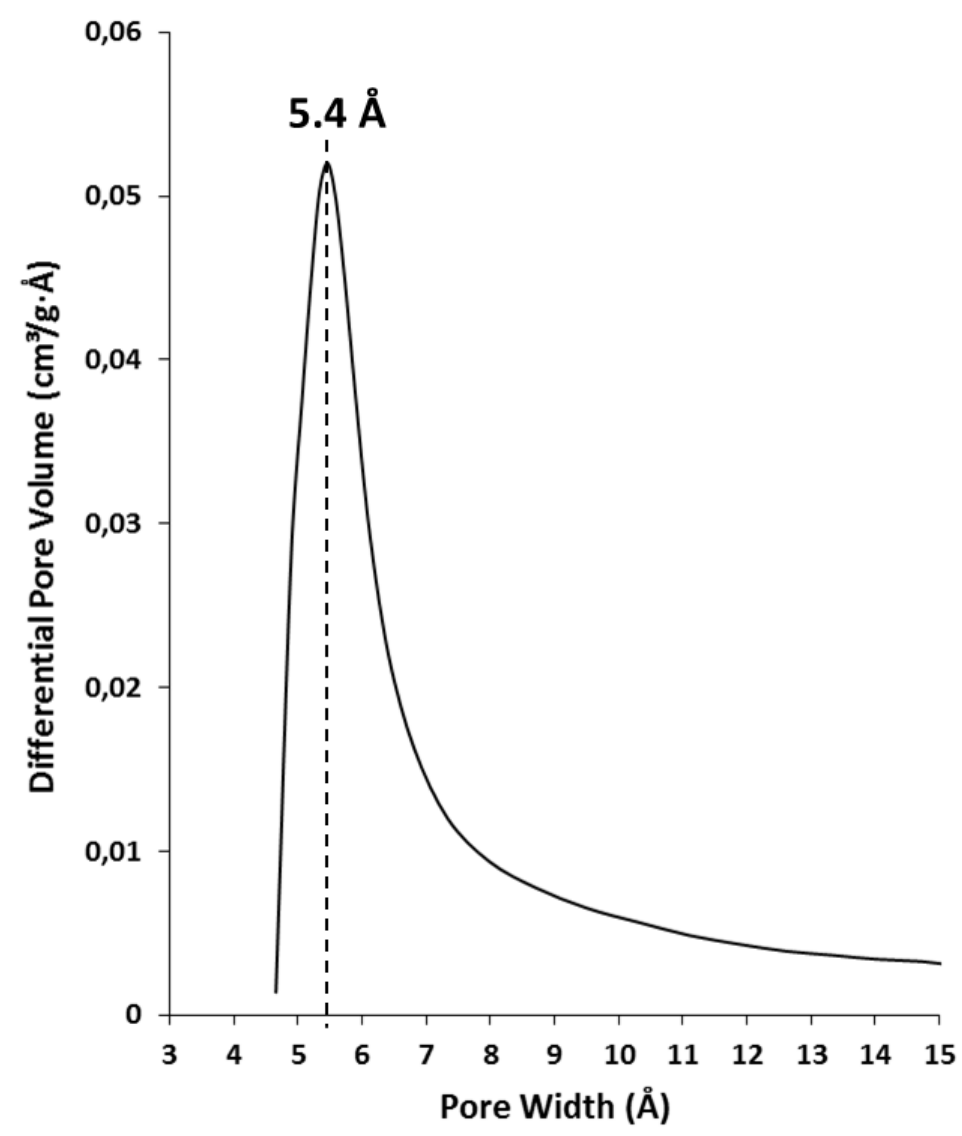


Figure 13. $\mathrm{PXRD}$ patterns of the as-prepared $\mathrm{Cu}$-containing layered $\mathrm{CDO}$ material $(\mathrm{Cu}-$ PreCDO) and its condensed form after being calcined in air (Cu-CDO).

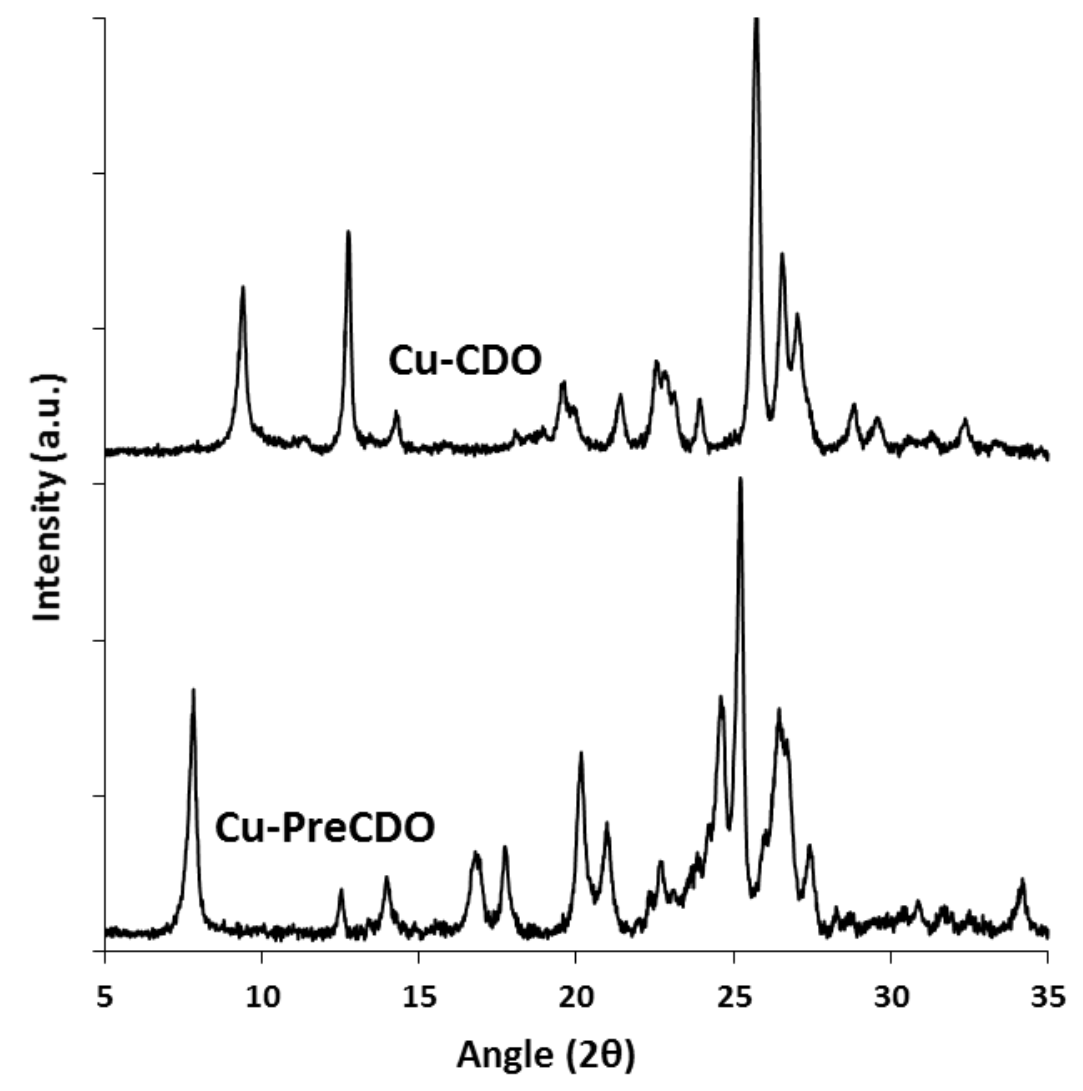


Figure 14: Diffuse-reflectance UV-Vis spectrum of the as-prepared Cu-containing layered CDO material (Cu-PreCDO).

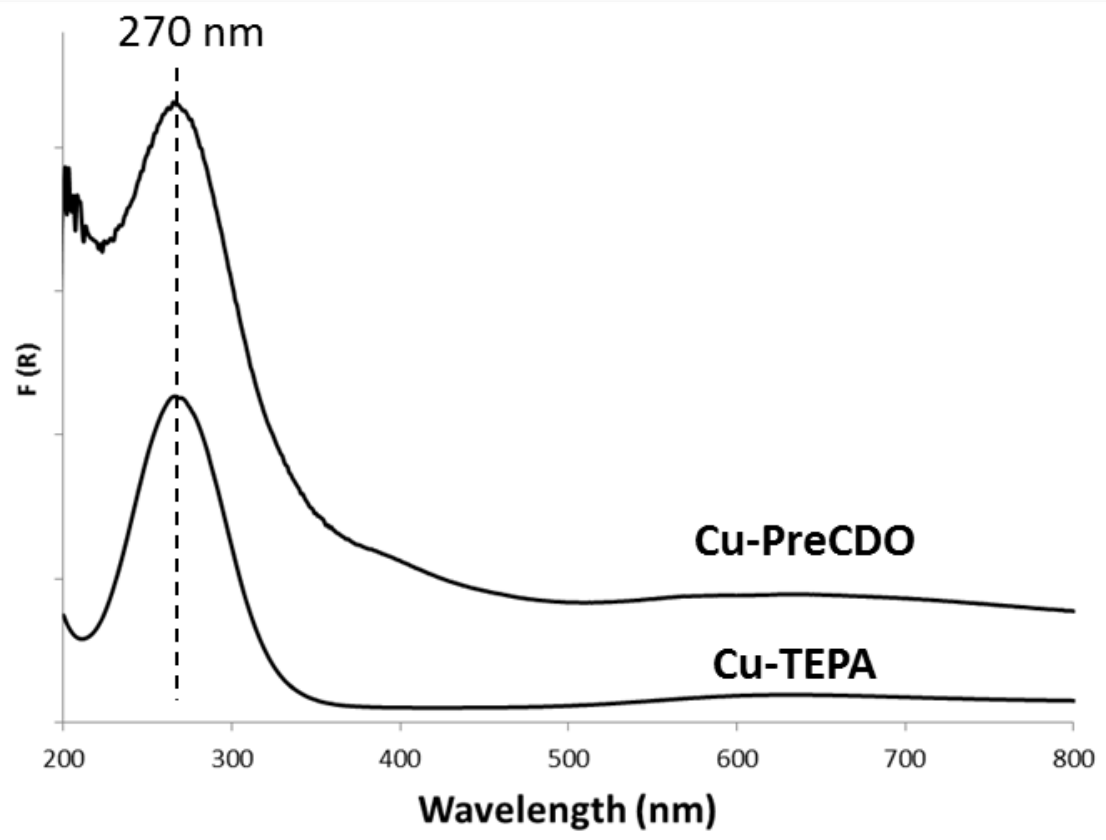


Figure 15. Catalytic activity for the SCR of NOx of the Cu-CDO material.

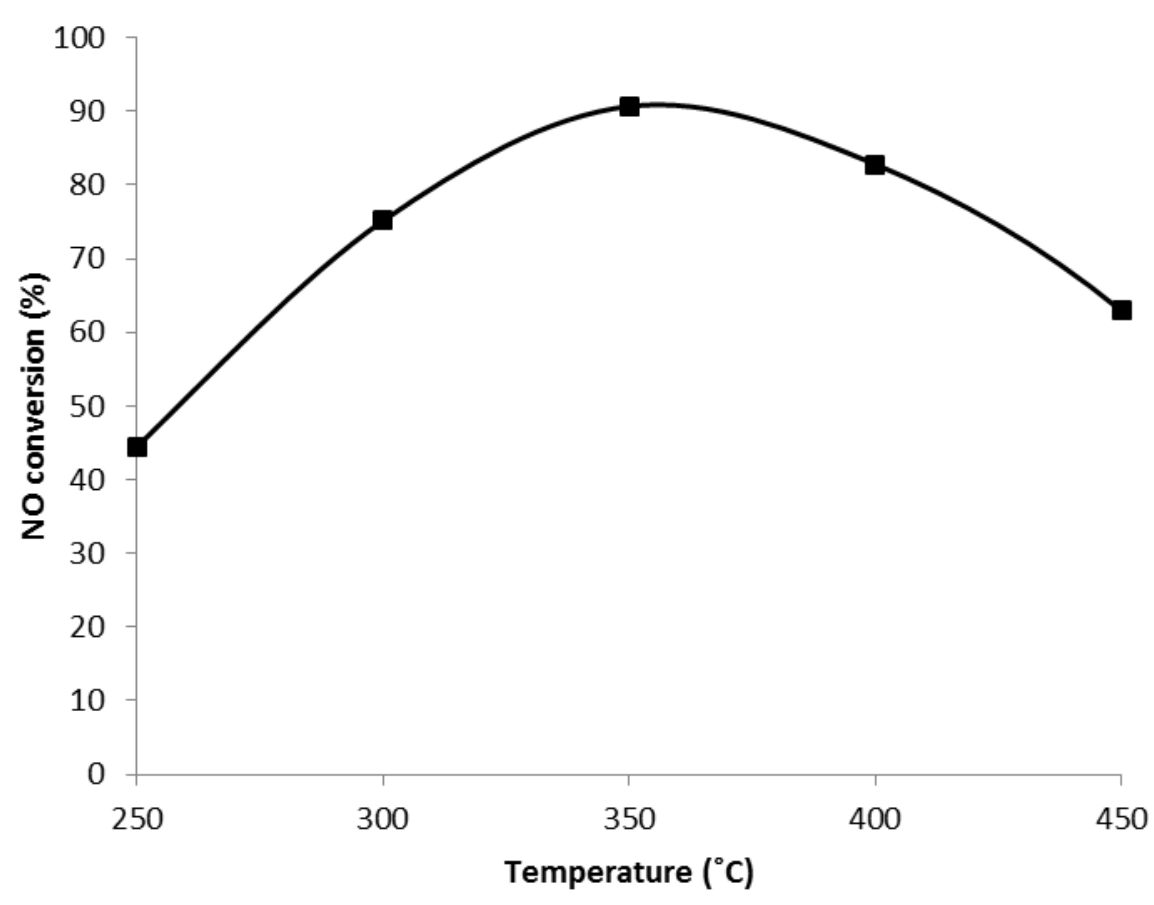


Figure 16: Hydrogen transfer ratios in the conversion of methanol at $400^{\circ} \mathrm{C}$ and WHSV: $0.8 \mathrm{~h}^{-1}$.

CDO_1

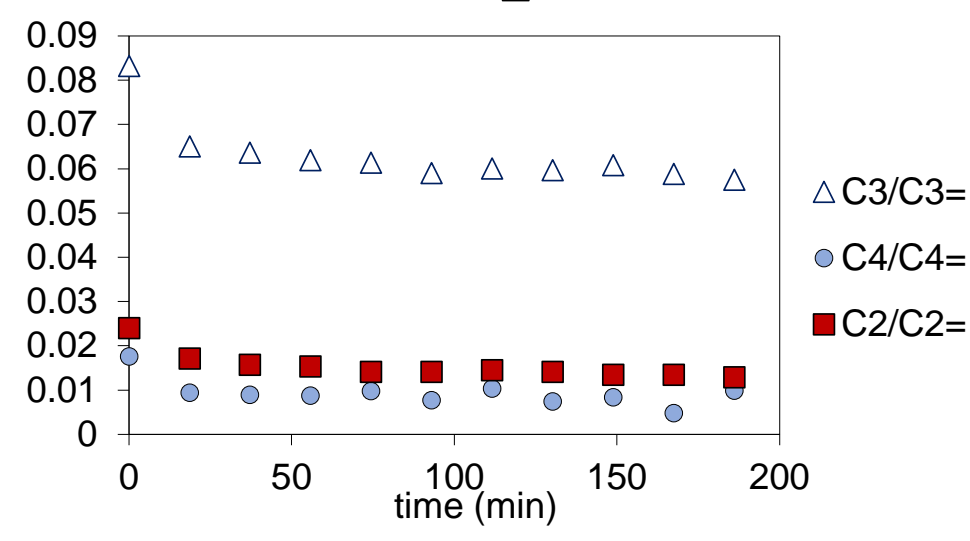

IEZ-CDO_1

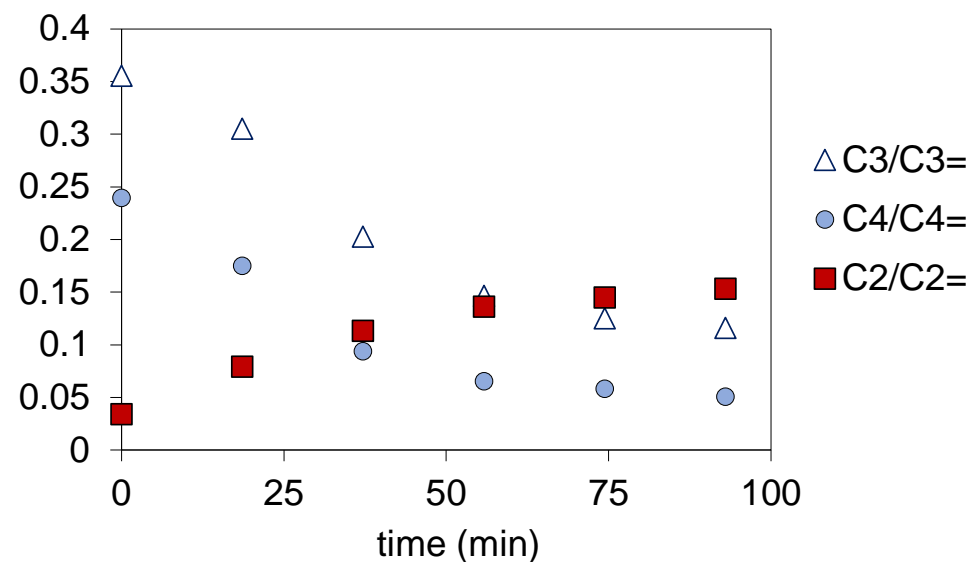

IEZ-CDO_2

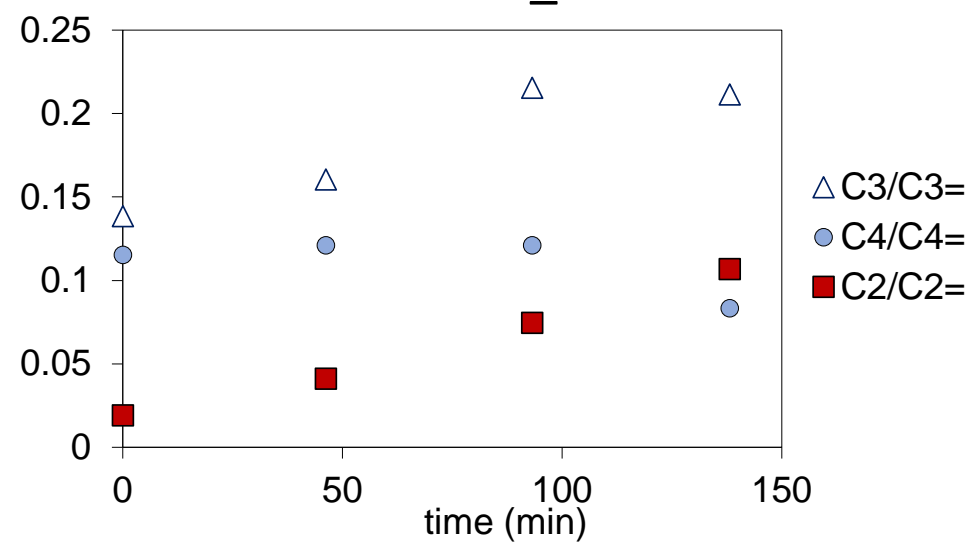


Table 1. Elemental analysis of the as-prepared CDO-type zeolites.

\begin{tabular}{cccccc} 
Sample & OSDA & \%wt N & \%wt C & \%wt H & C/N \\
\hline PreCDO_1 & OSDA2 $(\mathrm{C} / \mathrm{N}=8)$ & 2.11 & 13.90 & 2.94 & 7.68 \\
PreCDO_2 & OSDA2 $(\mathrm{C} / \mathrm{N}=8)$ & 2.25 & 14.90 & 3.07 & 7.74 \\
PreCDO_3 & OSDA1 $(\mathrm{C} / \mathrm{N}=7)$ & 2.74 & 16.21 & 3.41 & 6.90
\end{tabular}

Table 2. Chemical analyses of CDO-type zeolite.

\begin{tabular}{ccc} 
Sample & Si/Al & \%wt Cu \\
\hline PreCDO_1 & 14.2 & --- \\
CDO_1 & 14.2 & --- \\
IEZ-CDO_1 & 19.2 & --- \\
PreCDO_2 & 32.1 & --- \\
CDO_2 & 32.1 & --- \\
IEZ-CDO_2 & 38.2 & --- \\
PreCDO_3 & 47.3 & --- \\
CDO_3 & 47.3 & --- \\
IEZ-CDO_3 & 55.6 & --- \\
Cu-PreCDO & 13.3 & 5.3
\end{tabular}

Table 3. Textural properties of the CDO-type zeolites in their calcined form measured by $\mathrm{N}_{2}$ adsorption.

\begin{tabular}{|c|c|c|c|}
\hline Sample & $\begin{array}{c}\text { BET } \\
\text { area } \\
\left(\mathrm{m}^{2} / \mathrm{g}\right)\end{array}$ & $\begin{array}{l}\text { Micropore area } \\
\qquad\left(\mathrm{m}^{2} / \mathrm{g}\right)\end{array}$ & $\begin{array}{l}\text { Micropore volume } \\
\qquad\left(\mathrm{cm}^{3} / \mathrm{g}\right)\end{array}$ \\
\hline CDO_1 & 268.4 & 198.2 & 0.09 \\
\hline IEZ-CDO_1 & 299.5 & 221.2 & 0.11 \\
\hline CDO_2 & 293.8 & 215.2 & 0.11 \\
\hline IEZ-CDO_2 & 316.3 & 253.0 & 0.12 \\
\hline
\end{tabular}


Table 4. Catalytic activity and product selectivity for the conversion of methanol for a reaction time of $10 \mathrm{~min}$ at $400^{\circ} \mathrm{C}$ and WHSV $=0.8 \mathrm{~h}^{-1}$.

Selectivity (\%)

\begin{tabular}{|c|c|c|c|c|c|c|c|}
\hline \multirow[b]{2}{*}{ Sample } & \multirow[b]{2}{*}{ Si/Al } & \multirow[b]{2}{*}{$\begin{array}{c}\text { Conv } \\
(\%)\end{array}$} & \\
\hline & & & C1+Para & $C 2=$ & $C 3=$ & C4= & C5+ \\
\hline CDO_1 & 14.2 & 22.2 & 9.9 & 31.9 & 15.3 & 26.1 & 16.7 \\
\hline IEZ-CDO_1 & 19.2 & 68.5 & 21.1 & 29.2 & 32.2 & 12.2 & 5.2 \\
\hline IEZ-CDO-2 & 38.2 & 93.7 & 18.4 & 32.9 & 32.5 & 11.3 & 5.0 \\
\hline
\end{tabular}


AUTHOR INFORMATION

\section{Corresponding Author}

Avelino Corma*, e-mail: acorma@itq.upv.es; Manuel Moliner*, e-mail:

mmoliner@itq.upv.es

\section{ACKNOWLEDGMENT}

This work has been supported by the Spanish Government-MINECO through " Severo Ochoa” (SEV 2012-0267), and MAT2015-71261-R, by the European Union through ERC-AdG-2014-671093 (SynCatMatch); and by the Generalitat Valenciana through the Prometeo program (PROMETEOII/2013/011). The authors thank Isabel Millet for technical support. 


\section{REFERENCES:}

(1) (a) C. S. Cundy, P. A. Cox, Micropor. Mesopor. Mater., 2005, 82, 1; (b) A. Corma, M. E. Davis, ChemPhysChem., 2004, 5, 304.

(2) (a) R. F. Lobo, S. I. Zones, M. E. Davis, J. Inclus. Phen. Mol. Rec., 1995, 21, 47; (b) M. Moliner, F. Rey, A. Corma, Angew. Chem., Int. Ed., 2013, 13, 880.

(3) B. Marler, H. Gies, Eur. J. Mineral., 2012, 24, 405.

(4) Y. Asakura, R. Takayama, T. Shibue, K. Kuroda, Chemistry, 2014, 20, 1893.

(5) A. J. Blake, K. R. Franklin, B. M. Lowe, J. Chem. Soc., Dalton Trans., 1988, 2513.

(6) T. Ikeda, Y. Akiyama, Y. Oumi, A. Kawai, F. Mizukami, Angew. Chem., Int. Ed., 2004, 43, 4892.

(7) L. Schreyeck, P. Caullet, J. C. Mougenel, J. L. Guth, B. Marler, Microporous Mater., 1996, 6, 259.

(8) A. Rojas, M. A. Camblor, Chem. Mater., 2014, 26, 1161.

(9) (a) M. E. Leonowicz, J. A. Lawton, S. L. Lawton, M. K. Rubin, Science, 1994, 264, 1910; (b) R. Millini, G. Perego, W. O. Parker, G. Bellusi, L. Carluccio, Microporous Mater. 1995, 4, 221.

(10) W. J. Roth, P. Nachtigall, R. E. Morris, P. S. Wheatley, V. R. Seymour, S. E. Ashbrook, P. Chlubna, L. Grajciar, M. Polozij, A. Zukal, O. Shvets, J. Cejka, Nat. Chem., 2013, 5, 628.

(11) Y. X. Wang, H. Gies, B. Marler, U. Muller, Chem. Mater., 2005, 17, 43. 
(12) J. E. Schmidt, D. Xie, M. E. Davis, Chem. Sci., 2015, 6, 5955.

(13) B. Marler, N. Stroter, H. Gies, Micropor. Mesopor. Mater., 2005, 83, 201.

(14) T. Moteki, W. Chaikittisilp, A. Shimojina, T. Okubo, J. Amer. Chem. Soc., 2008, $130,15780$.

(15) T. Ikeda, S. Kayamori, Y. Oumi, F. Mizukami, J. Phys. Chem. C, 2010, 114, 3466.

(16) D. L. Dorset, G. J. Kennedy, J. Phys. Chem. B, 2004, 108, 15216.

(17) A. Burton, R. J. Accardi, R. F. Lobo, M. Falcioni, M. W. Deem, Chem. Mater., 2000, 12, 2936.

(18) J. Song, H. Gies, Stud. Surf. Sci. Catal., 2004, 154A, 295.

(19) (a) P. Wu, J. Ruan, L. Wang, L. Wu, Y. Wang, Y. Liu, W. Fan, M. He, O.

Terasaki, T. Tatsumi, J. Am. Chem. Soc., 2008, 130, 8178; (b) J. Ruan, P. Wu, B. Slater, Z. Zhao, L. Wu, O. Terasaki, Chem. Mater., 2009, 21, 2904; (c) H. Gies, U. Muller, B. Yilmaz, T. Tatsumi, B. Xie, F. S. Xiao, X. Bao, W. Zhang, D. D. Vos, Chem. Mater., 2011, 23, 2545; (d) H. Gies, U. Muller, B. Yilmaz, M. Feyen, T. Tatsumi, H. Imai, H. Zhang, B. Xie, F. S. Xiao, X. Bao, Chem. Mater., 2012, 24, 1536.

(20) P. Guo, L. Liu, Y. Yun, J. Su, W. Wan, H. Gies, H. Zhang, F. S. Xiao, X. Zou, Dalton Trans., 2014, 43, 10593.

(21) M. Moliner, C. Martínez, A. Corma, Chem. Mater., 2014, 26, 246.

(22) C. Martínez, A. Corma, Coord. Chem. Rev., 2011, 255, 1558.

(23) (a) B. Yilmaz, U. Muller, M. Feyen, H. Zhang, F. S. Xiao, T. De Baerdemaeker, B. Tijsebaert, P. Jacobs, D. De Vos, W. Zhang, X. Bao, H. Imai, T. Tatsumi, H. Gies, 
Chem. Commun., 2012, 48, 11549; (b) E. Hida, Y. Oumi, T. Ikeda, A. Kawai, T. Yokoyama, F. Mizukami, T. Sano, J. Cer. Soc. Jpn., 2005, 113, 424.

(24) T. De Baerdemaeker, H. Gies, B. Yilmaz, U. Muller, M. Feyen, F. S. Xiao, W. Zhang, T. Yokoi, X. Bao, D. E. De Vos, J. Mater. Chem. A, 2014, 2, 9709.

(25) (a) F. S. Xiao, B. Xie, H. Zhang, L. Wang, X. Meng, W. Zhang, X. Bao, B. Yilmaz, U. Muller, H. Gies, H. Imai, T. Tatsumi, D. De Vos, ChemCatChem, 2011, 3, 1442; (b) L. Wang, Y. Wang, Y. Liu, H. Wu, X. Li, M. He, Peng Wu, J. Mat. Chem., 2009, 19, 8594; (c) J. Ruan, P. Wu, B. Slater, O. Terasaki, Angew. Chem., Int. Ed., 2005, 117, 6877.

(26) A. M. Beale, F. Gao, I. Lezcano-Gonzalez, C. H. Peden, J. Szanyi, Chem Soc Rev., 2015, 44, 7371.

(27) (a) R. Martinez-Franco, M. Moliner, J. R. Thogersen, A. Corma, ChemCatChem, 2013, 5, 3316; (b) L. Ren, L. Zhu, C. Yang, Y. Chen, Q. Sun, H. Zhang, C. Li, F. Nawaz, X. Meng, F. S. Xiao, Chem. Commun., 2011, 47, 9783; (c) N. Martin, C. R. Boruntea, M. Moliner, A. Corma, Chem. Commun., 2015, 51, 11030; (d) R. MartinezFranco, M. Moliner, A. Corma, J. Catal., 2014, 319, 36.

(28) M. Deimund, J. Schmidt, M. E. Davis, Top. Catal., 2015, 58, 416.

(29) Q. Zhu, J. N. Kondo, R. Ohnuma, Y. Kubota, M. Yamaguchi, T. Tatsumi, Micropor. Mesopor. Mater., 2008, 112, 153. 
TABLE OF CONTENTS.

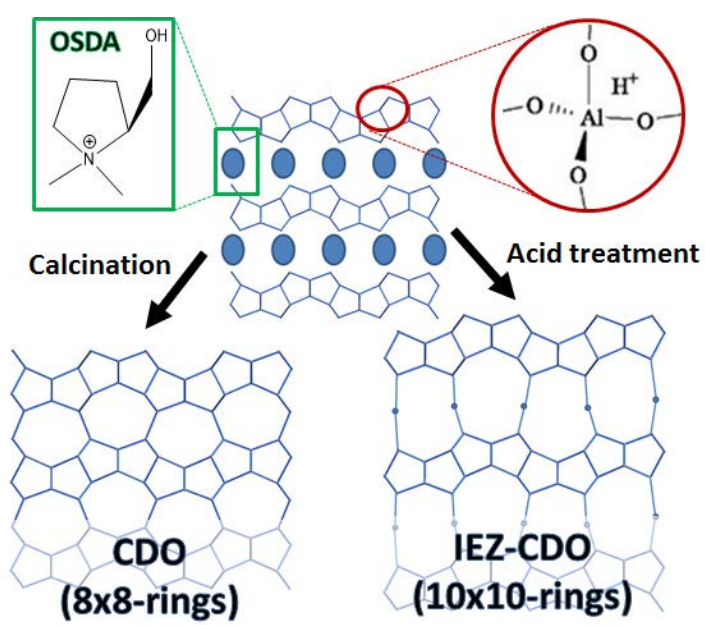

